\title{
WestVirginiaUniversity
}

THE RESEARCH REPOSITORY @ WVU

Graduate Theses, Dissertations, and Problem Reports

2018

\section{Climate Science Literacy: A Study of Climate Programs' Usability}

Amber Rochelle Williams

West Virginia University, aewilliams@mix.wvu.edu

Follow this and additional works at: https://researchrepository.wvu.edu/etd

Part of the Geography Commons

\section{Recommended Citation}

Williams, Amber Rochelle, "Climate Science Literacy: A Study of Climate Programs' Usability" (2018).

Graduate Theses, Dissertations, and Problem Reports. 3732.

https://researchrepository.wvu.edu/etd/3732

This Thesis is protected by copyright and/or related rights. It has been brought to you by the The Research Repository @ WVU with permission from the rights-holder(s). You are free to use this Thesis in any way that is permitted by the copyright and related rights legislation that applies to your use. For other uses you must obtain permission from the rights-holder(s) directly, unless additional rights are indicated by a Creative Commons license in the record and/ or on the work itself. This Thesis has been accepted for inclusion in WVU Graduate Theses, Dissertations, and Problem Reports collection by an authorized administrator of The Research Repository @ WVU. For more information, please contact researchrepository@mail.wvu.edu. 


\title{
Climate Science Literacy: A Study of Climate Programs' Usability
}

\author{
A. R. Williams \\ Thesis submitted \\ to the Eberly College of Arts and Sciences \\ at West Virginia University
}

in partial fulfillment of the requirements for the degree of

Master of Arts in

Geography

Eungul Lee, Ph.D., Chair

Jamison Conley, Ph.D.

Jamie Shinn, Ph.D.

Department of Geology and Geography

Morgantown, West Virginia

2018

Keywords: Programs' Usability, Climate Science, Panoply, GrADS, Geography

Copyright 2018 Amber Rochelle Williams 


\section{ABSTRACT \\ Climate Science Literacy: A Study of Climate Programs' Usability A. R. Williams}

Literacy is an important facet of understanding how undergraduate college students comprehend climate science. This research, conducted at West Virginia University, examines the usability of climate data in three commonly used climate programs to reduce the prominent knowledge gap in climate science literacy about college students.

The objective of this research is to investigate the knowledge gap in climate science literacy by conducting focus group surveys to examine the usability of programs that use climate datasets. The three programs used in this research were the NOAA online tool, NASA's Panoply data viewer, and GrADS programmable tool. The NOAA tool is based online with built in datasets. Panoply and GrADS are software programs that require external datasets. Each program was tested for usability. This research employed a mixed methods explanatory design to address research questions. To evaluate programs' usability, the data from face-to-face interview and paper-based survey were quantitatively analyzed. To evaluate attitude toward three climate programs, the data from semi-structured interviews were qualitatively analyzed. My initial expectation was that participants would have difficulty with some of the programs used by climate scientists, and this would negatively impact their attitude towards the programs after attempting to use them. Identifying these difficulties would provide a possible way to address climate science literacy for undergraduate college students. The research encountered a major limitation of volunteer recruitment for participation in both surveys and interviews. As an artifact of this limitation, the quantitative and qualitative analysis contained a small sample size of eight participants.

The results of the quantitative and qualitative analysis revealed that participants found NOAA and Panoply relatively easier to work with than GrADS programmable tool, which was found to be the most challenging program to use by participants. Participants chose the NOAA online tool as having the highest usability among the three programs. Although the NOAA online tool was determined to be the easiest to use, qualitative results revealed Panoply data viewer was the most preferred program due to a better map output. The overall attitudes towards each program were: NOAA is easy to use, Panoply is somewhat easy to use, and is preferred, and GrADS is challenging to use and requires training to use successfully.

This assessment of the usability of these three commonly used climate programs in teaching and research of climatology can aid in the advancement of climate science literacy. Panoply should be used as an introductory program to give students a good representation of climate programs. Results indicate that when students find the climate programs accessible they pay more attention in climate data analysis. Panoply can capture attention by creating aesthetically pleasing maps. The NOAA online tool, which had the highest usability among all the three programs, should be used as an introductory teaching tool for climate science. GrADS programmable tool can be used as an advanced statistical climate-based program. These recommendations support the advancement of climate science literacy, and address misconceptions and mistrust of climate science by providing students with a way to do analysis for themselves. 


\section{Acknowledgements}

I start by thanking Dr. Eungul Lee for his support, insight, patience, and help with my thesis. He encouraged me to achieve my goals and guided me along the way. I am very thankful and grateful to have had him as my advisor. Thank you Dr.Lee. I thank my committee, Dr. Jamison Conley and Dr. Jamie Shinn, for their advice, time, and support. Thank you Dr.Shinn for guiding me in IRB and for all of your feedback. Thank you Dr.Conley for your feedback and overall support. I would also like to thank my Climatology Lab mates, Jothiganesh Shanmugasundaram, Yaqian He, and Shobha Yadav for giving me advice and encouragement toward accomplishing my goals. I also thank my fellow graduate student Lee Ann Nolan for your encouragement and help in this process. Lastly, I want to say thank you to my family and friends for believing in me and cheering me on. 


\section{Table of Contents}

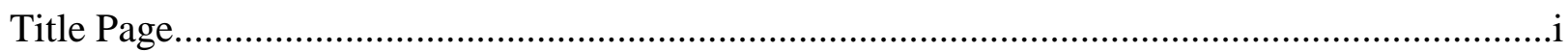

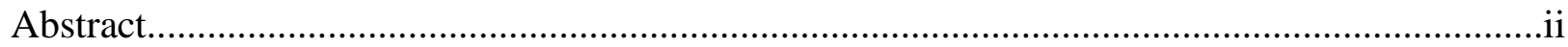

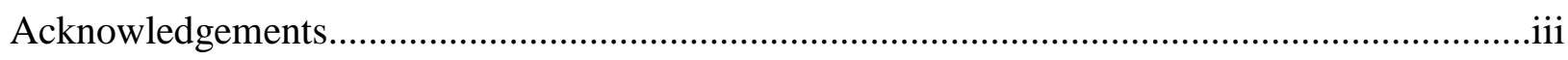

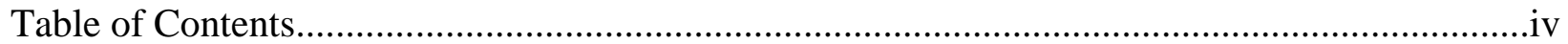

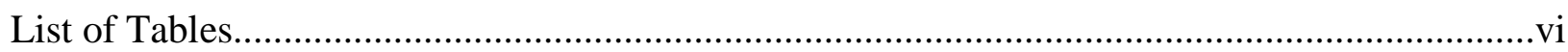

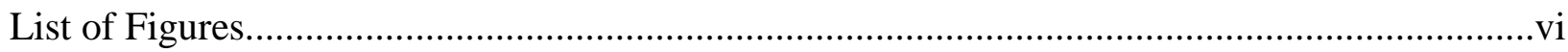

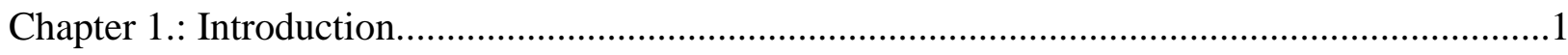

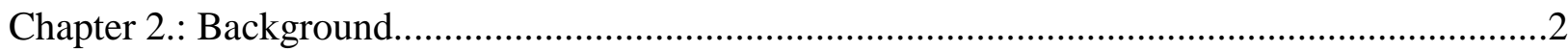

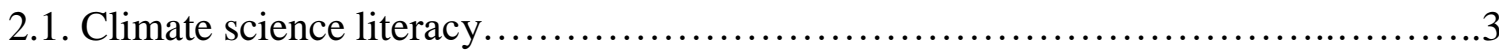

2.2. Emergent study: A case study for climate literacy..............................

2.3. Next Generation Science Standards.............................................

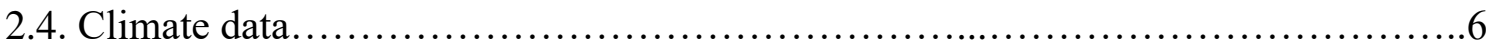

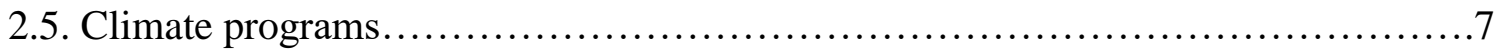

Chapter 3.: Hypothesis/Research Questions......................................................................

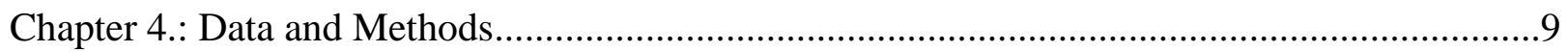

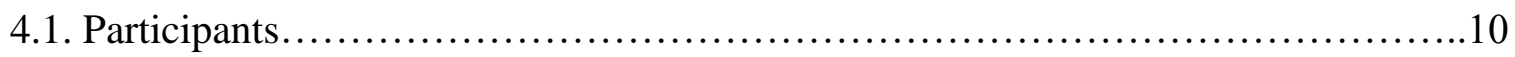

4.2. Quantitative methods........................................................

4.3. Qualitative methods............................................................

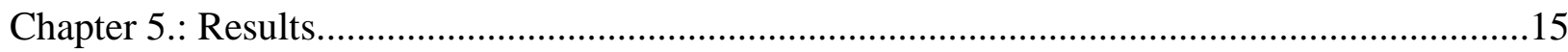

5.1. Quantitative Analysis....................................................... 17

5.1.1. Visual inspection: Box plots......................................17

5.2. Parametric and non-parametric statistics....................................24 
5.3. Qualitative analysis.

5.4. Non-participant observation.....................................................

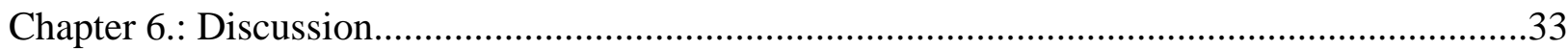

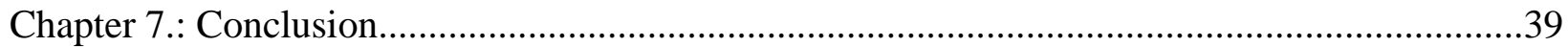

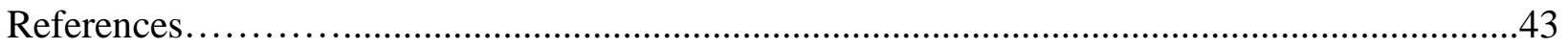

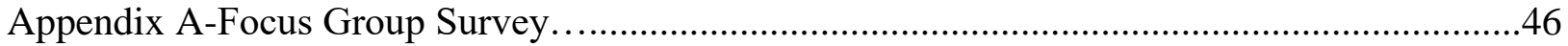

Appendix B-Grid Analysis and Display System code......................................................57

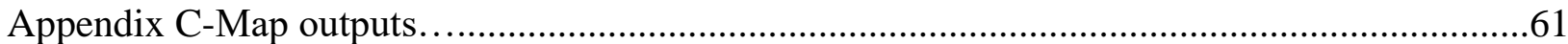




\section{List of Tables}

Table 5.1 P-values of significance tests of three programs to questions 1-5 (Group 1).........25

Table 5.2 P-values of significance tests of three programs to question 7 (Group 2)............26

Table 5.3 P-values of significance tests of three programs to questions 6,8 and 9 (Group 3)

GrADS has been omitted from this group, because no participants were able to produce a map.

\section{List of Figures}

Figure 5.1 Home state of participants.............................................

Figure 5.2 Undergraduate majors of participants...................................... 17

Figure 5.3 Box plots of scores for nine questions by participant for NOAA Online Tool........18

Figure 5.4 Box plots of scores for nine questions by participant for Panoply Data Viewer......19

Figure 5.5 Box plots of scores for nine questions by participant for GrADS .................20

Figure 5.6 Box plots of scores of all eight participants by each question for NOAA Online

Tool

Figure 5.7 Box plots of scores of all eight participants by each question for Panoply..........22

Figure 5.8 Box plots of scores of all eight participants by each question for GrADS...........23

Figure 5.9 Tukey-Kramer test groups are determined by similarity for Group $1 \ldots \ldots \ldots \ldots \ldots .26$

Figure 5.10 Question 7 Tukey-Kramer grouping...................................27

Figure 5.11 Word Cloud based on frequency of word use for question 5 "Which of the programs

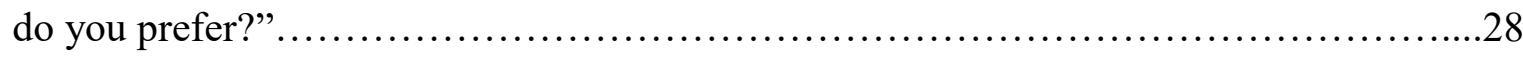

Figure 5.12 Word Cloud based on frequency of word use for question 2 "Which was the easiest to use or best to use?".

Figure 5.13 Word Cloud based on frequency of word use for question 1 "Which Program did you find to be the most difficult?".

Figure 5.14 Word Cloud based on frequency of word use for question 4 "How did it make you

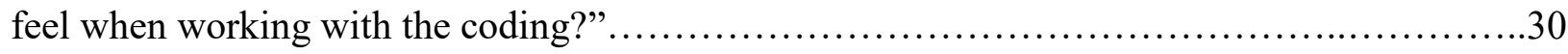




\section{Introduction}

Too often gaps in knowledge inhibit an understanding of the world around us. One significant knowledge gap is the lack of understanding of climate science. Gaps in climate science literacy include misconceptions of how our climate works, misperceptions of climate science, and distrust of both data sources and scientists. One of the factors that promote this gap is a difficulty to find and use climate data without prior training. This project seeks to understand the knowledge gap with the usability of three commonly used climate programs and suggest possible solutions. The aim of this research is to analyze and determine how the programs' usability contributes to improving climate science literacy of undergraduate college students.

This project grew out of my personal experience with using climate data for classes and research projects. I know how difficult it is to find data because this issue plagued my first semester of graduate school. It was hard to believe that data would be so hard to find. I came to terms with these issues after finding an accessible climate dataset. Specifically, I figured out how to transform that dataset in a NetCDF format, a data format commonly used in Climate science, into ArcGIS (Geographic Information Systems), a mapping suite commonly used in Geography. This was a semester-long process of adapting a program to assess the usability of climate datasets. This experience prompted me to question the use of climate programs to analyze climate data. This project was driven by a curiosity to see if others would have the same difficulties and lead me to the research aim of my master's study.

Climate science literacy has typically focused on terminology and misperceptions surrounding the understanding of climate systems, with K-Gray learners. K-Gray learners include students in the K-12 system through adult learners (Dupigny-Giroux, 2010). This project adds to the research on climate science literacy by focusing on the understanding of usability in climate-based programs to improve the overall understanding of climate science. A continued challenge is discerning the relationship between climate science literacy and geography education at the high school level. This is due to the lack of centralization for these topics in high school science classes.

A critical part to understanding how knowledge gaps form in climate science is to recognize how climate science is taught at the high school level. One of the issues concerning the 
teaching of climate science is that it falls under different subjects, including Earth Science and Physical Science. Because there is not typically a secondary/high school class that focuses specifically on climate science as a standard subject, a knowledge gap exists that impacts how undergraduate college students comprehend climate science. In addition, concepts important for understanding the physical mechanisms of climate science, such as pressure and temperature, are taught in other subjects and are not directly connected to the study of the climate. Lastly, like many other sciences, students often struggle with concepts in climate science. As such, students might not connect these principles to the climate. For this reason, it is important to address how students learn concepts in geography and its sub-disciplines in general (Guo, 2014). More specifically, it is also important to learn how students can find credible datasets and use technology to visualize the often-complex conceptualizations of climatic phenomena, and thus improve their climate science literacy. This project investigated these issues by surveying and interviewing undergraduate college students to determine the usability of three climate data programs. It asked two research questions:

1. How usable are climate-based programs to undergraduate college students?

2. What are student's attitudes toward these programs, specifically the most difficult program chosen by the participants?

\section{Background}

In this section I provide a background to situate the importance of and to introduce key topics of my research. I do this through positionality, being able to evaluate my perspective and

experience and how that effects the research. Also, I identify what climate science literacy is and then I explore an emergent study at West Virginia University. Here I provide a background context of expected knowledge of high school/secondary students according to Next Generation Science Standards (NGSS). I then give information on climate data and identify and discuss climate programs used in this research. 


\section{Positionality}

As a researcher it is important to evaluate my own position in relation to the research. I must identify characteristics that played a role in my research and my writing to situate my thesis (England, 1994). To do this I reflected on my status as a master's student and my experience with the programs I ask participants to use.

I am a master's student at West Virginia University, who did my undergraduate degree at West Virginia University. The programs used in this research were the ones I learned to use first when working with climate datasets. My status as a master's student gave me an outsider positionality, as I am not an undergraduate student. Data was something I found complicated to work with for students at any class level. I struggled to find data when I was an undergraduate and graduate student. Using the three programs from this research taught me how to analyze climate data. I believe that they improved my climate science literacy by providing me with skills and tools that I did not know of. Having had challenges and triumphs with these programs I wanted to see if participants would find some of the same challenges or benefits with them, and to see how usable the programs really are.

\subsection{Climate science literacy}

Climate science literacy is being able to understand Earth's systems, critically think and use climate-based information, being able to "communicate about climate...in a meaningful way" and being able to "make informed... decisions with regard to actions that may affect climate" (National Oceanic and Atmospheric Administration, 2009). Though knowledge gaps exist for each of these areas, this research is primarily focused on the students' perception of climate programs' usability. Bedford (2015) found that overall levels of climate science literacy were low among undergraduate students. This is concerning as there are 17 million undergraduate students estimated to be enrolled as of fall 2018 in the United States at either a 2year or a 4-year institution (National Center for Education Statistics, 2018).

It is assumed that the primary reason for this low literacy is that science education is impacted by misconceptions and false understandings of climatic phenomena (Harrington, 2008). 
Students need to be able to think critically and formulate questions about climate science, but face barriers with communication of the science. The barrier in effective communication exists due to discrepancies in the terminology and communication platforms. Dupigny-Giroux (2010) pointed out some discrepancies on learning within climate science, difficulty with terminology, misconceptions of cause and effect, and issues with curriculum centralization. A possible solution offered to address issues with climate science curriculum is to improve the usability of climate programs, to make them more effective communication platforms.

Shealy, Godwin and Gardner (2017, p.4) argue that misconceptions have to do with a lack of education. As a result, "Climate science is not well-understood by middle and high school students in the U.S..." Plutzer et al. (2016) highlight the issue that even though teachers at the middle and high school stages are willing to teach science around climate change, they typically have a limited understanding and background in major climate change factors themselves. This passes on these misconceptions and uncertainties in climate science to high school students who go on to become undergraduate students. As a result, even while researchers agree that climate literacy is important for understanding the world around us, there remains a gap in dissemination of data and scientific information between scientists and the general public, including teachers and their students (Miler \& Sladek, 2011).

\subsection{Emergent study: A case study for climate literacy}

In a pilot project run at West Virginia University, on which I am a co-investigator, Caretta et al. (under review) identify three aspects of climate literacy among a specific group of undergraduate students. First was the perceptions of the students toward climate change, second was the mistrust of scientists, and third was the possibility of technology. For example, one individual participating in this research referred to climate science a sort of "pseudo" science, claiming that data is just a means to end for scientists or for deniers to prove or disprove that climate change exists. This assumption identifies how students perceive the dissemination of results. Another participant stated, "Most science dramatizes it (data) to fit their view point" (Focus Group Participant, 2018 from Caretta et al. under review). The quote shows how there is a mistrust of scientists, as well as a mistrust of science in general. The participants of Caretta et 
al. research were unable to fully trust or find credible information to do with climate change. For example, one person said,

"Scientists kind of seem like this faceless, just elite group outside of everyone else that has this secret knowledge that no else is capable of having, doing research that no one else could possibly do." (Focus Group Participant, 2018 from Caretta et al. under review)

This quote shows how some students feel about climate science, with climate research being seen as an exclusive club. Another participant said of hurricane season activity in 2017, "I'm not a climatologist so I can't look at the data for those hurricanes and say this is caused by climate change." (Focus Group Participant, 2018 from Caretta et al. under review). It is interesting that students do not feel they could find and use a credible data source to analyze climatic phenomena or trust those who can analyze it. How can mistrust about the science of climate change and climate science more generally be curbed? There is no clear answer for this.

A possibility is that the use of technology could provide a way to teach students how to use climate data on their own, making it seem more accessible than previously thought. If students could be given the tools that climate scientists use, they may be better able to address credibility concerns and test data for themselves rather than relying on a system of blind trust in scientists. To do this, we must first understand how students interact with the information available. Conducting focus groups on programs' usability provides a way to both inform students and analyze that interaction. If there is no trust, there can be no progress.

\subsection{Next Generation Science Standards}

A report from the Climate and Energy Literacy Summit (National Center for Science Education, 2012) discussed a new set of standards that were based on the National Research Council's Framework for K-12 Science Education that could help in the development and implementation of climate science curricula in 26 participating states. These standards were known as the Next Generation Science Standards (NGSS). Released in 2013, these standards would provide an approach to addressing climate literacy. NGSS could be the way to improve the current curricula for young students to understand and interact with climate science in a more 
meaningful way. However, the NGSS curriculum primarily focused on the basics of climate science and thus cannot be considered the only way to address the knowledge gap (Lem, 2016).

In the standards for middle school students (grades 6-8), it states that students should be able to do three things: 1) "Collect data to provide evidence for how the motions and complex interactions of air masses results in changes in weather conditions," 2) "Develop and use a model to describe how unequal heating and rotation of the Earth cause patterns of atmospheric and oceanic circulation that determine regional climates," and 3) "Ask questions to clarify evidence of the factors that have caused the rise in global temperatures over the past century" (NGSS, 2016). While the NGSS goals are what students should be learning about in climate science, there is often a lack of trust or understanding behind the credibility of graphical representations of climatic phenomena shown to students in curriculum. Therefore, climate data and programs can further aid students in the learning of the three focuses outlined by the NGSS by providing an interactive platform for students to gain a better understanding.

\subsection{Climate data}

Greater accessibility of climate data can also be a way to understand issues within climate science literacy. Overpeck et al. (2011) stated that even with a large volume of climate data available publicly in a digital form, it may be hard to obtain. They also mentioned that some knowledge of how climate systems behave is important in the use of climate datasets. This makes climate data's accessibility and usability more challenging for those who are not trained or actively taking a class about climate science. Although publicly available climate data may be hard to find, it is still important to teach students how to effectively use new technologies, such as utilizing ArcGIS in geography classroom in higher education (Lemke \& Ritter, 2000).

While a numerous amount of climate data is technically available to the public through online platforms, it is not necessarily accessible. One almost needs to be trained on how to find these datasets to download and use them. As such, the general lack of training available for students poses a problem to their climate science literacy. How can students expect to be science literate if they are unable to find data? Several researchers agree that students need to able to think critically and form questions about climate science to improve their overall literacy (NGSS 2016; Harrington 2008). Data can help them do this. Shepardson et al. (2012, p.14) state that 
analyzing climate data can be an effective way “... to communicate about and contextualize climate data and ideas from a climate system perspective." This idea supports the goal of this project to analyze climate literacy of students through having them actively working with a given climate dataset. The interaction of students with datasets is important to understanding how undergraduate college students use different climate-based programs to analyze climate data.

\subsection{Climate programs}

There is a need to understand how students use and combine geographic information (Guo, 2014). Within climate science literacy, there is a specific call for better ways to address misconceptions of climate (McCaffrey \& Buhr, 2013). Data accessibility can be that avenue with which to address students' knowledge gap.

In this study, three climatic programs were considered to identify any usability gaps of the software, which could be a source of knowledge gap in climate science literacy. Among the three programs, one program is an online interactive tool. This online tool is the monthly/seasonal climate composite tool in the NOAA/Physical Science Division (PSD) Interactive Climate Analysis and Plotting Web-Tools. This tool uses the climate datasets from the National Centers for Environmental Prediction (NCEP) and North American Regional Reanalysis (NARR). The NOAA online tool has multiple parameter identifications that can be set to reach a better understanding of climate system interaction. However, the data interface might be confusing at first, by requiring multiple year entry to be placed in the correct order. This tool plots the monthly and seasonal composite means of climatic variables. NARR data in this tool is available for Jan 1979-present (National Oceanic and Atmospheric Administration, 2018). It is important to note that during the collection of results the webpage used to show the map output on NOAA's online tool changed. Participants had to scroll down the length of the webpage to find the map, where previously the map would appear at the top of that page.

Among the three programs, two climatic programs used in this study were computerbased programs. One desktop-based program was Panoply data viewer. Panoply is a program developed by NASA's Goddard Institute. This program allows gridded climate data to be shown in an interactive map output, and the parameters interface is somewhat complex. This intermediate complexity is due the multiple tabs and functions available with Panoply (National 
Aeronautics and Space Administration, 2017). It could be a good visualization tool for both scientists and non-scientists.

Another desktop-based program is the Grid Analysis and Display System (GrADS, 2017). GrADS is a programmable (script-based) interface for sophisticated analysis, which has been used mainly by climate scientists. This program also offers a more sophisticated statistical analysis of a given dataset. However, this program might be complex to use, especially for those not trained on how to correctly use it.

\section{Hypothesis and Research Questions}

The two aims of this research are: 1) to determine if using climate-based programs will enhance college undergraduate students' understanding of climate science and thus their climate science literacy and 2) to identify their attitude toward the programs, primarily the program students consider most difficult. To achieve these objectives, I conducted semi-structured interviews using the three climate programs: NOAA online tool, NASA Panoply data viewer, and GrADS programmable tool.

My hypothesis is that using different climate-based programs will significantly affect the ability of students to understand climate science. This research will be able to help address the knowledge gap of programs' usability in climate science literacy for undergraduate students. The focus for climate programs' usability lied in the effectiveness of the three programs to address climate science literacy. Further, it is hypothesized that the NOAA online tool and NASA Panoply might be effective in enhancing climate science literacy, due to the understandable interface and less complex graphics. For students, GrADS might be the most difficult of these programs to use and understand which will impact students' understanding of climate science. The participants in the survey are expected to identify Panoply and the online tool as being easier to use and have mixed feelings on GrADS. To determine programs' usability of climate data and participant's attitude to the climate programs, two research questions were addressed quantitatively and qualitatively, respectively:

1. How usable are climate-based programs to undergraduate college students? 
2. What are student's attitudes toward these programs, specifically the most difficult program chosen by the participants?

\section{Data and Methods}

Temperature data from NARR was used within GrADS and NASA Panoply. NARR is daily collected data that is produced under a subsection of NOAA (National Centers for Environmental Prediction, 2018). The current available data spans about 39 years, last updated in 2018. NARR data is in a grid scale of approximately 0.3 degree by 0.3 degrees (Mesinger et al., 2006). Its primary purpose is to convey climatologic/weather information. Specifically, the dataset used in both programs was for 2-meter air temperature for January 1979 and January of 2018, at the monthly scale. Air temperature at 2 meter (near the surface level) was used for the NOAA online tool, which was the lowest atmospheric level for the online tool (National Oceanic and Atmospheric Administration, 2018).

All three programs used the same dataset (i.e., NARR) to avoid any data inconsistency issues and to provide students with an example of how all three programs process differently with the same dataset information. A single variable was used to keep consistency in data analysis using the three programs. Temperature was chosen because most people can identify with it as a climate variable. It is often spoken about in daily conversation as small talk (Cuncic \& Gans, 2018) and would be a good variable for students to relate their daily life to climate. Using the same dataset helps to determine the usability of each program. Usability in this research was measured by how challenging it was to import data, perform tasks to interact with the program interface (e.g., subtract monthly temperature between two months, set temperature range, and set latitude and longitude), and to identify how easy or challenging that interface was to use. Usability was impacted by the ability of participants to produce a map.

This study employed a mixed methods approach to address the research questions (Leavy 2017) to integrate both quantitative and qualitative methods, and was based on an explanatory research design (Creswell \& Clark, 2007). An explanatory research design is the collection of quantitative and qualitative data, which is then interpreted to receive an aggregate of results. This 
research design requires that quantitative data be collected before qualitative data. I used an explanatory design because participants first had to complete the quantitative survey before I could perform semi-structured interviews.

This approach has been used to combine both a quantitative set of data and a qualitative set of data to give a more robust answer to the research questions (Clark et al., 2008). By combing quantitative survey results with qualitative interview results I was able to identify each programs' usability, and the reasons each program is or is not usable. I used a mixed methods approach because it gives the research more freedom to address the research questions (Johnson \& Onwuegbuzie, 2004) with that more robust set of data. Instead of only receiving quantitative or qualitative results I was able to develop a fuller understanding of the climate programs. Using this approach was pivotal in completing my research due its small sample size. This study combined the quantitative and qualitative data and methods to provide insight into climate science literacy.

The first of my two research questions were analyzed using quantitative methods. This research question was answered by the analysis of programs' usability based on visual and statistical analysis methods, Boxplots, One-way ANOVA, Wilcoxon test, and Tukey-Kramer test. Focus groups were conducted to analyze the usability of the three programs in a paper-based survey format. The second research question was answered by qualitative analysis of programs' usability based on coding and non-participant observation methods. To address this research question, individual semi-structured interviews were conducted. The qualitative method of 'think aloud' was used after each interview to shape the semi-structured questions.

\subsection{Participants}

My original goal was to have a sample size of 20-25 participants per focus group, out of 3 possible groups, but not that many chose to participate. Five focus groups, at an hour and a half to two hours, were conducted achieving a total of eight participants. The small size of participants is examined further in my discussion section, where I reflect and discuss the limitations faced by this study. All focus groups surveys were completed as a laboratory style exercise that reviewed all three programs' usability. 
The selection criteria for participants were that they must be an undergraduate student currently enrolled at West Virginia University. The participants must have taken or be in the process of taking an introductory geography course. Participants must also be 18 years of age. Because of the addition of specific parameters this type of sampling was considered as nonrandom and was known as purposive sampling (Teddlie \& Yu, 2007).

\subsection{Quantitative methods}

A quantitative analysis was performed with the data from focus groups surveys. As stated earlier, the survey consisted of 3 parts: demographic questions, questions concerning the usability for each of the three programs, and map interpretation questions. Statistical methods including box and whisker plots, an analysis of variance (ANOVA) test, a Wilcoxon test, and a Tukey-Kramer test were performed on the survey results.

\section{Data collection}

Data collection was done through surveys. These surveys were in a laboratory/ questionnaire style format. Surveys were conducted on paper in a focus group setting through face-to-face interview methods (Clifford et al., 2016). Paper based methods were chosen to simplify computer use while participants perform the laboratory exercise (Statistics Canada, 2003). Survey questions were scored on a scale of 1 to 10, with 1 being challenging and 10 being easy. The results were collected for nine of the survey questions and were grouped based on the purposes of questions, details of groups are described in the last paragraph of section 4.2.

\section{Data analysis}

The data collected from surveys was analyzed by four different methods. First, box plots of the data were made to analyze programs usability by individual participant scores to each question and by each question scores of all participants for the three climate programs. Next, a one-way ANOVA (Field, Miles \& Field, 2012) test was performed to find the statistical difference in means among the three programs. A level of significance for accepting or rejecting the null hypothesis was evaluated by $p$-values. The null hypothesis assumed that all programs 
have an equal usability mean (Moore \& McCabe, 1999). The ANOVA test directly evaluates the validity of the null hypothesis (McGrew, Lembo \& Monroe, 2014).

The Wilcoxon test was used to analyze rank sums for a group. This test is non-parametric and does not assume that the scores follow a normal distribution. The Wilcoxon statistic is preferable for small sample sizes. It identifies the mean rank of each program and then produces a $p$-value (McGrew, Lembo \& Monroe, 2014). The final test is the Tukey-Kramer test, which is used for pairwise comparisons of all pairs of means against one another. The test determines if the programs are like one another by comparing means, places them into groups based upon similarity of those means, and provides $p$-values for the differences between all pairwise program combinations (Hayter, 1984). For this research three comparisons were made, e.g., NOAA vs. GrADS, Panoply vs. GrADS, and NOAA vs. Panoply. To analyze these results the survey questions were divided into three groups based on purpose of the question to address the first research question.

Group 1 determined the usability of each program, which included question 1 through 5 on the survey.

1. On a scale of 1 to 10 how challenging or easy was it to import the dataset?

2. On a scale of 1 to 10 how challenging or easy was it to subtract 1979 from 2018 ?

3. On a scale of 1 to 10 how challenging or easy was it to adjust the temperature range?

4. On a scale of 1 to 10 how challenging or easy was it to set the longitude and latitude?

5. On a scale of 1 to 10 how would you rate the interface of this program?

Group 2 consisted of only question 7, which "directly" asked the usability of each program.

7. On a scale of 1 to 10 how would you rate the usability of (program name)?

Group 3 contained the questions 6, 8 and 9, which were related to the exported map.

6. On a scale of 1 to 10 how challenging or easy was it to export the map once created?

8. On a scale of 1 to 10 is this map easy or challenging to interpret?

9. On a scale of 1 to 10 is the scale bar easy or challenging to interpret? 
The response rate for each program was inconsistent, as all participants responded to all the questions for NOAA. Panoply had all participants respond to all the questions except for question 9 with response rate of 7/8 participants. GrADS had one participant, who did not respond to any of the questions, was removed and this resulted in a response rate of 7/8 for questions 1-5 (Group 1), 6/8 for question 7 (Group 2), and 4/8 participants for questions 6, 8, and 9 (Group 3).

\subsection{Qualitative methods}

Participants of the focus group surveys were then interviewed using semi-structured interview methods. All interviews were recorded using a digital recorder and were transcribed and hand coded later. Notes on participant interaction and body language were also collected to evaluate the second research question.

\section{Data collection}

Think aloud methods were employed after participants completed the focus group surveys. This method has been used as a rich source of verbal data (Fonteyn, Kuipers \& Grobe, 1993). The term think aloud comes from the verbalization of a participant's process during an interview. This method is simply slowing the process and making the participant carefully think about the task (Solomon, Barnard \& Sandberg, 1994). Think aloud methods are used to understand a cognitive process. They usually take place in a comfortable setting.

Interviews were based on basic journalistic questions (Snider, 2010), and semi-structured interview methods (Cohen \& Crabtree, 2006; Gill et al., 2008). The purpose for a basic journalistic style questioning and semi-structured interviews is to maintain a form of control with the researcher and have a set form of questions to compare all the interviews. During their interviews participants can add additional information to the questions and comment on anything they felt to be relevant. This was done to help identify any other possible patterns that may come out during the interview process. It also allowed me to ask questions based on participant responses to the interview guide. 
Focus groups were conducted in a computer lab. Each focus groups' participants would sit in the first row, of two, with at least one computer between them. The maximum number of participants per focus group never exceeded two participants. Participants completed the survey then gave it to me. Then I sat with each participant individually in the second row of computers and asked them the five questions (see data analysis). I recoded the interviews on a voice recorder. I also took notes while conducting the interview. Participants were asked if recording was okay, all agreed. In addition, I took field notes tracking time spent on completing the survey and observing their body language, as described in the next paragraph. Participants were aware I was taking notes, but I did not tell them I was observing their body language as it could have influenced the results of my observations. Following each focus group, I reread my notes and marked down anything I could remember during the survey and interview of focus groups.

During the focus groups non-participant observation methods were used to evaluate participant interaction with the programs. To aid in this observation I noted participant body language as they took the survey. Non-participant research method was used to study the behavior of participants while they were completing the surveys (Cooper, Lewis \& Urquhart, 2004). To analyze the non-verbal collection method, body language was used to identify how participants conducted themselves during the focus groups. Body language is a form of nonverbal communication, also known as kinesics, that can give deeper insight into participant interaction through posture, movement of the body, and sound (Denham \& Onwuegbuzie, 2013; Vaughan 1982). I observed participants body language to identify markers of stress, negative emotional response or subconscious blocking as indicators of difficulty. Observing body language is important because it is something we as humans do subconsciously. It displays the physical emotions that we may not even know we are showing.

\section{Data analysis}

Participants were interviewed after each focus group, all the interviews were transcribed, and data analysis was done via coding from the transcriptions. Coding was done to identify patterns within the interview transcriptions (Saldana, 2009). Coding was done by hand and by use of a word cloud generator called WordItOut. Deductive coding was used in this analysis, because I had a specific set of questions that I wanted answered. This predefined my codes (Flaim \& Speckart, 2016), which were 'Difficult', 'Easiest to use', 'Best to use', 'Coding', 
'Prefer', 'NOAA', 'Panoply', and 'GrADS'. These codes were used to create word clouds. The word clouds were then used to select key terms to evaluate for each question. Five questions were asked following completion of the survey.

1. Which program did you find to be the most difficult?

2. Which was the easiest to use or best to use?

3. Any other thought about these programs in general?

4. How did it make you feel when working with the coding?

5. Which of the programs do you prefer?

These questions were another way to verify what participants said in their survey responses. All question responses were put into an online word cloud generator. I used word clouds to help identify the frequency of use of each participant response, for all eight participants by question. This then provided results to analyze student's attitudes toward the climate programs.

\section{Results}

There were two primary results from this research. The first was the result of using the quantitative analysis ranking system for nine of thirteen questions answered by participants. The questions on map interpretation are not included here because only two of the three programs had maps produced. Questions were asked about certain aspects of each program to understand the programs' usability. These were answered on a scale of 1 to 10 , with 1 being challenging, 5 being neutral, and 10 being easy, I analyzed the results for quantifying the variations between the different climatic programs by applying box plots and then by performing parametric (ANOVA and Tukey-Kramer test) and non-parametric (Wilcoxon test) methods. The quantitative analysis supported my first research question. To address my second research question, qualitative analysis was used to understand the interaction of students with these programs and also to determine usability. This was done through a word analysis of semi-structured interview results and through observation of body language of participants during the surveys. 
The first step for all results was to identify the demographics of the eight total participants. The majority of participants (five) were from West Virginia (Figure 5.1). There was an even mixture of participants (three for each) who reported having studied climate science in high school and those who did not, while the remaining said "they studied some concepts for a very short period of time".

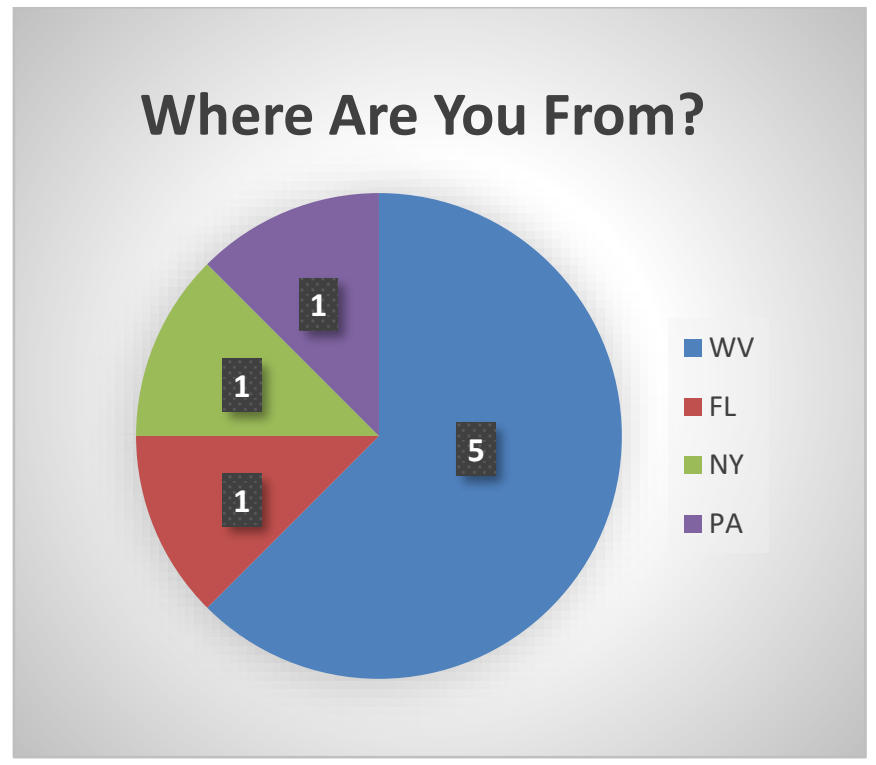

Figure 5.1. Home state of participants.

Participants' class levels were predominately sophomore and seniors, with only one freshman. Four were Geography majors, two were Environmental Geoscience, and one for Anthropology and Sociology each (Figure 5.2). Seven participants have taken climate related courses at West Virginia University such as Physical Geography, Climate and Environment, Climatological Analysis, and Global Environmental Change. Only one participant reported not having completed any physical geography or climate related course at the time of the survey. 


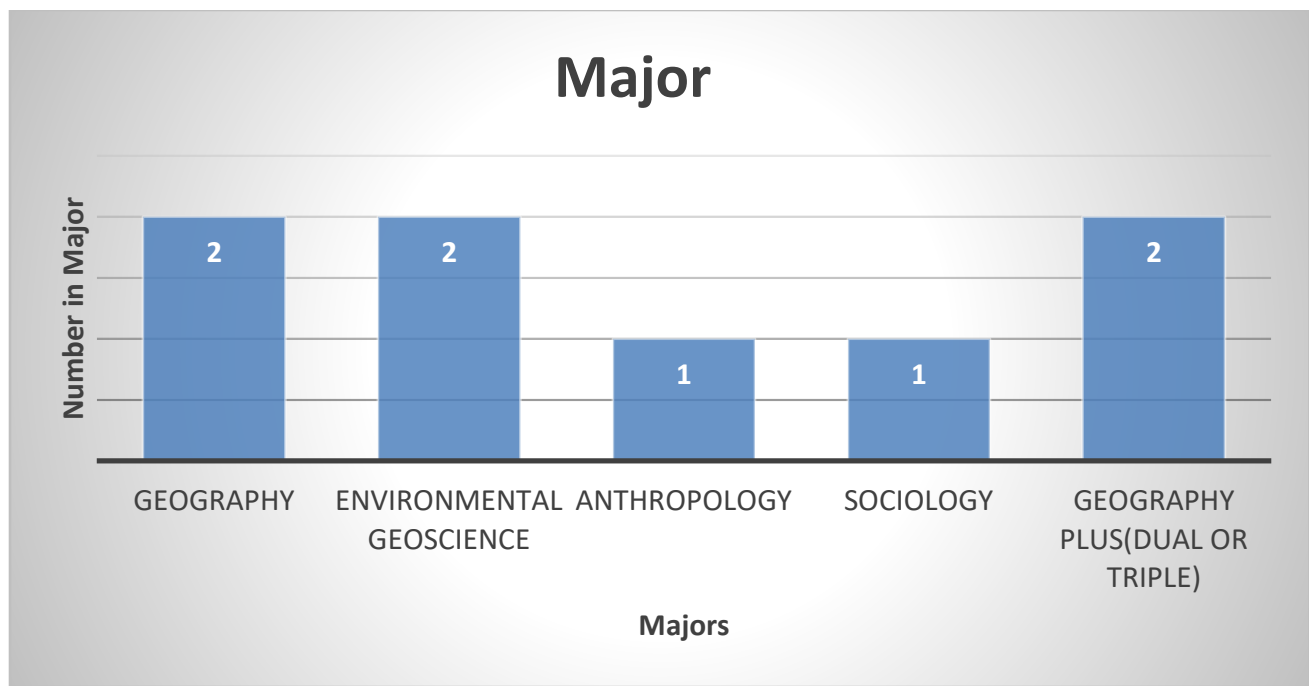

Figure 5.2. Undergraduate majors of participants.

\subsection{Quantitative Analysis}

The quantitative results were represented first in Box plots by participants and by questions for each program, and then in the statistical outputs from ANOVA, Wilcoxon test, and the Tukey-Kramer test.

\subsubsection{Box plots}

Programs usability by participants

The scores of all nine questions were calculated by each participant using Box plots. The results showed for the three climate programs, respectively. 


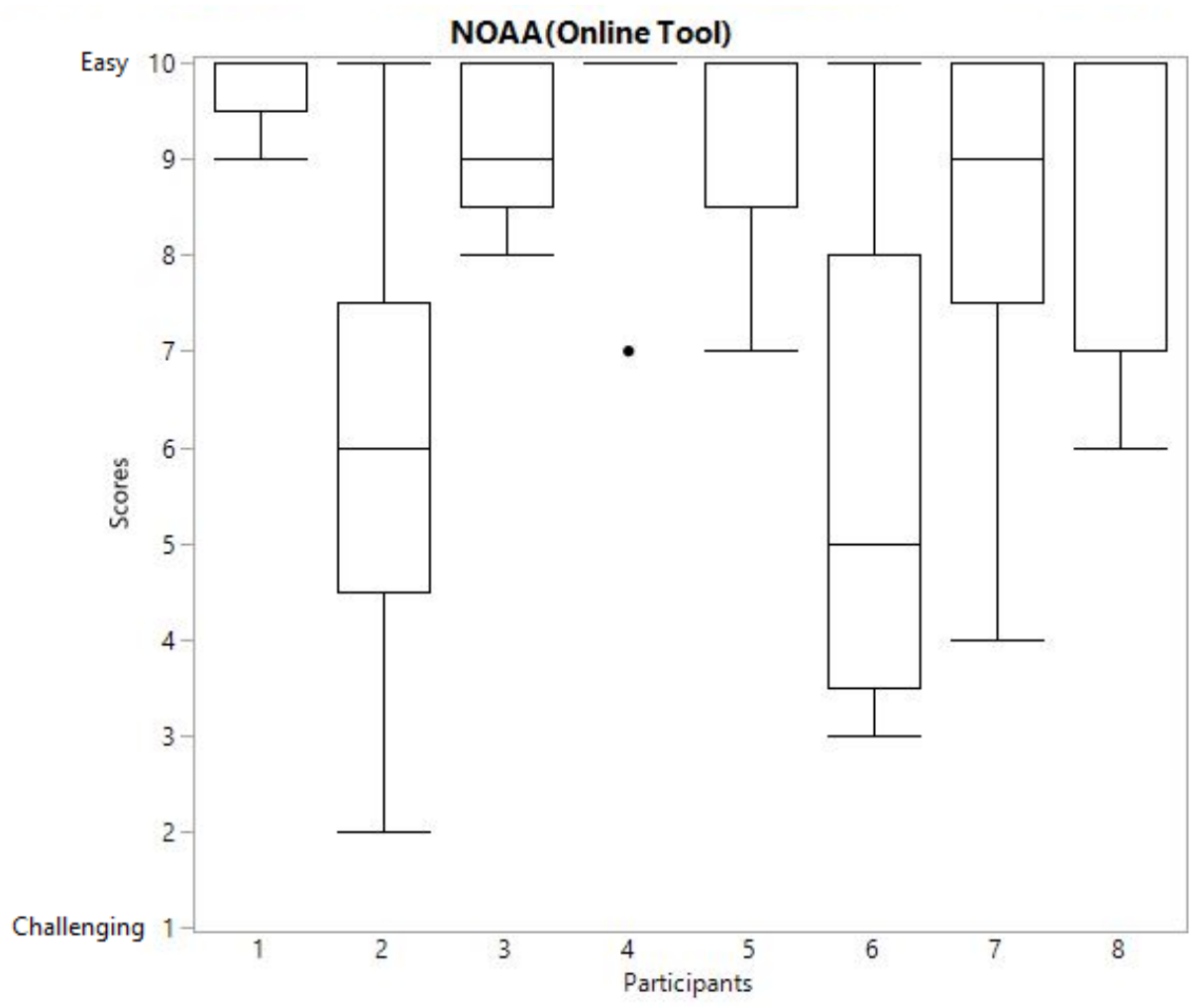

Figure 5.3. Box plots of scores for nine questions by participant for NOAA Online Tool.

The first program is the NOAA Online Tool. As you can see in Figure 5.3, all eight participants said this program was either easy or neutral overall, with most participants responding easy. Two of the participants' responses answered as neutral, with participant two reporting "there was some difficulty while using this program". 


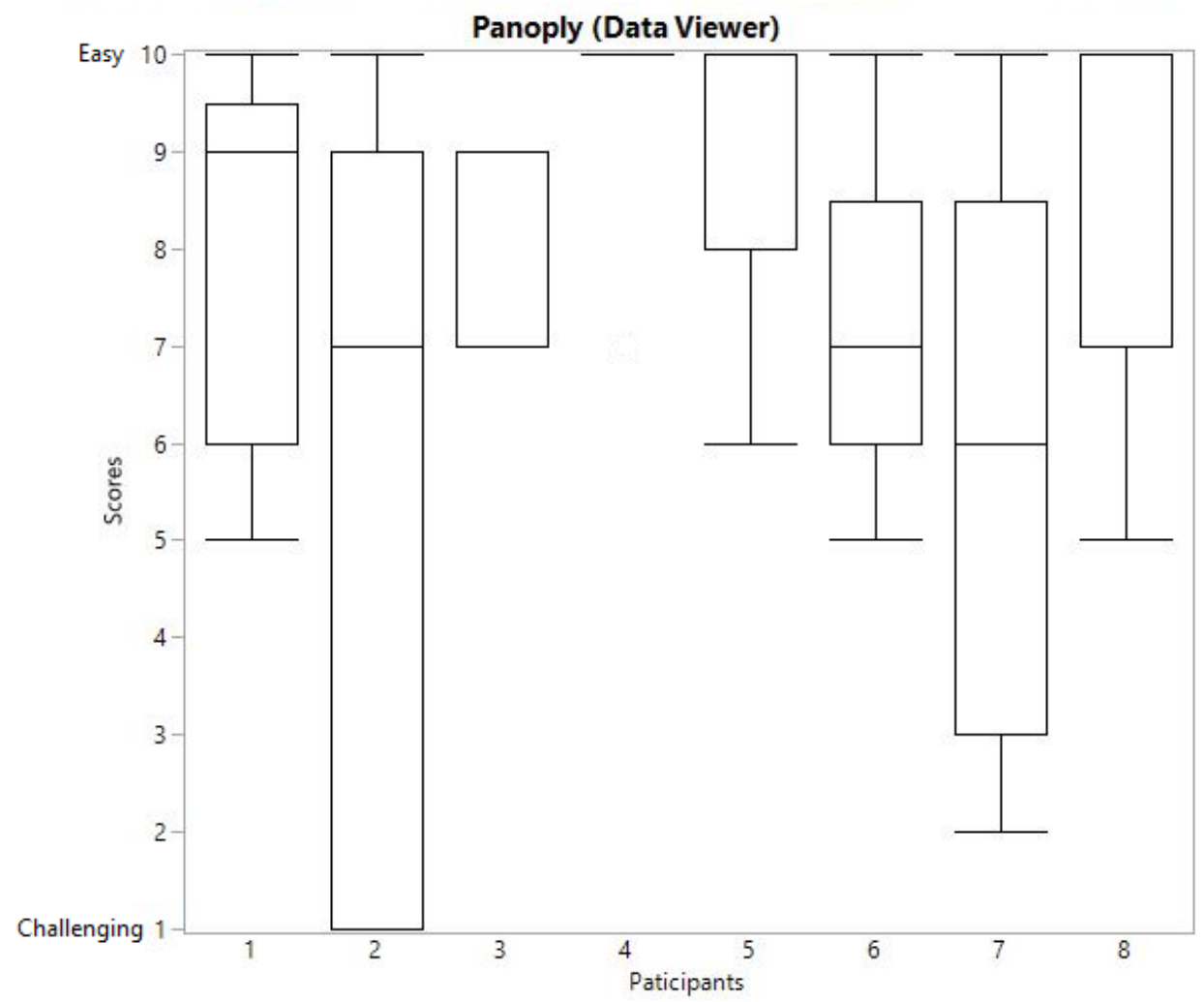

Figure 5.4. Box plots of scores for nine questions by participant for Panoply data viewer.

Second is NASA's Panoply data viewer. The participant responses were mixed as two said the program was easy, four responding easy to neutral, and two participants responding with some difficulty. However, overall the majority of participants responded with this program being in-between easy and neutral. 


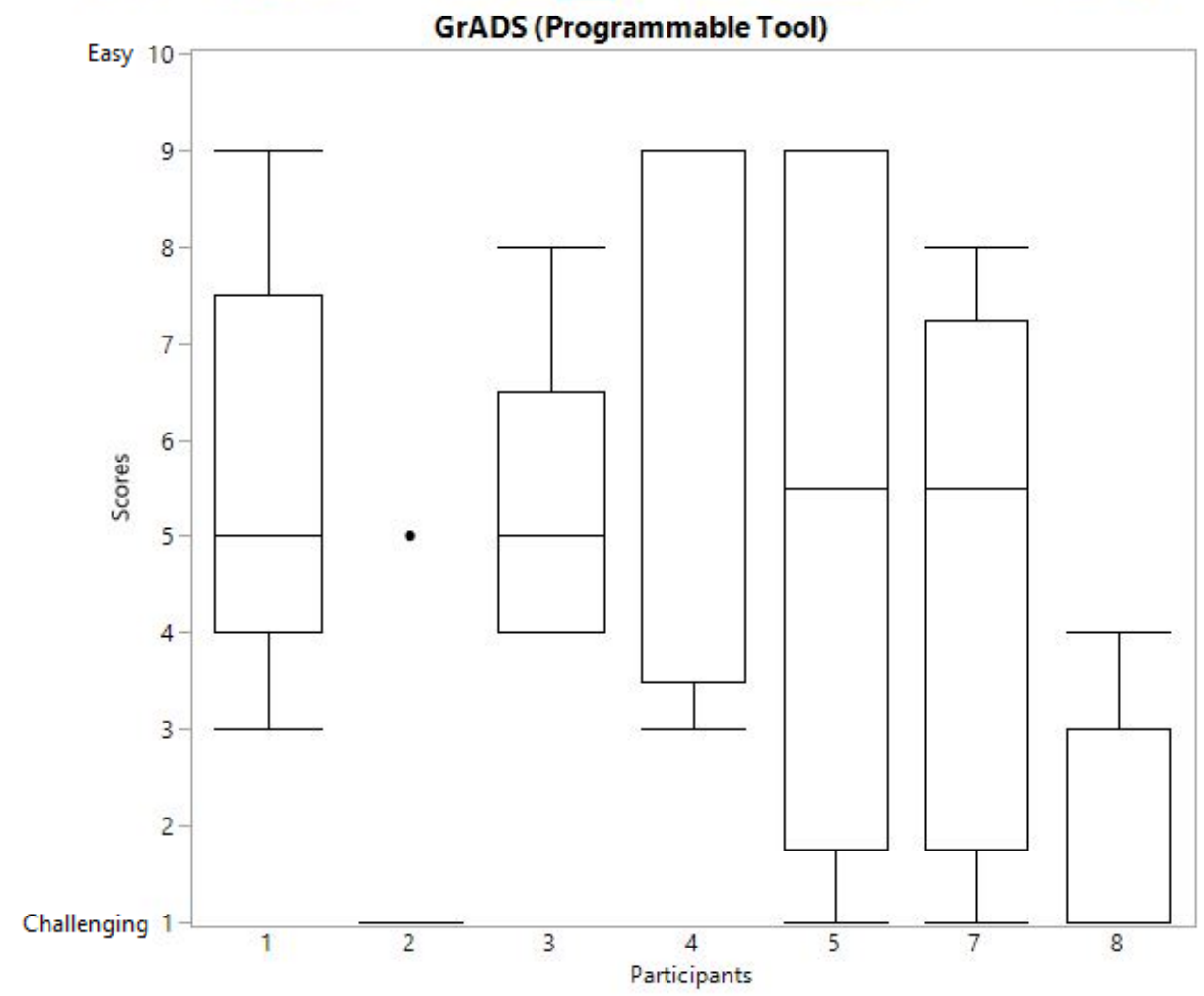

Figure 5.5. Box plots of scores for nine questions by participant for GrADS.

The third program is GrADS, which is a programmable tool. Participants said that GrADS was challenging to neutral with the majority responding challenging. Participant 6 is missing from this box plot, as they did not provide a response for GrADS. Four of seven participants responded that GrADS was more challenging with some reporting neutral to easy levels. This skew is most likely due to missing values as participants were not able to answer some questions. Further examination of these results is referenced in the discussion section.

\section{Programs usability by question}

The following box plots are the scores of all eight participants by each question for the three programs. Each question was made up of eight participant responses, except for GrADS (see GrADS analysis). The questions were grouped into 3 categories, based on purpose, for analysis. Questions 1 through 5 were the determining factors of usability as identified in the data and methods section (Group 1). Questions 6, 8, and 9 had to do with map output and map 
interoperation (Group 3). Question 7 directly asked the participants about their usability of each program (Group 2).

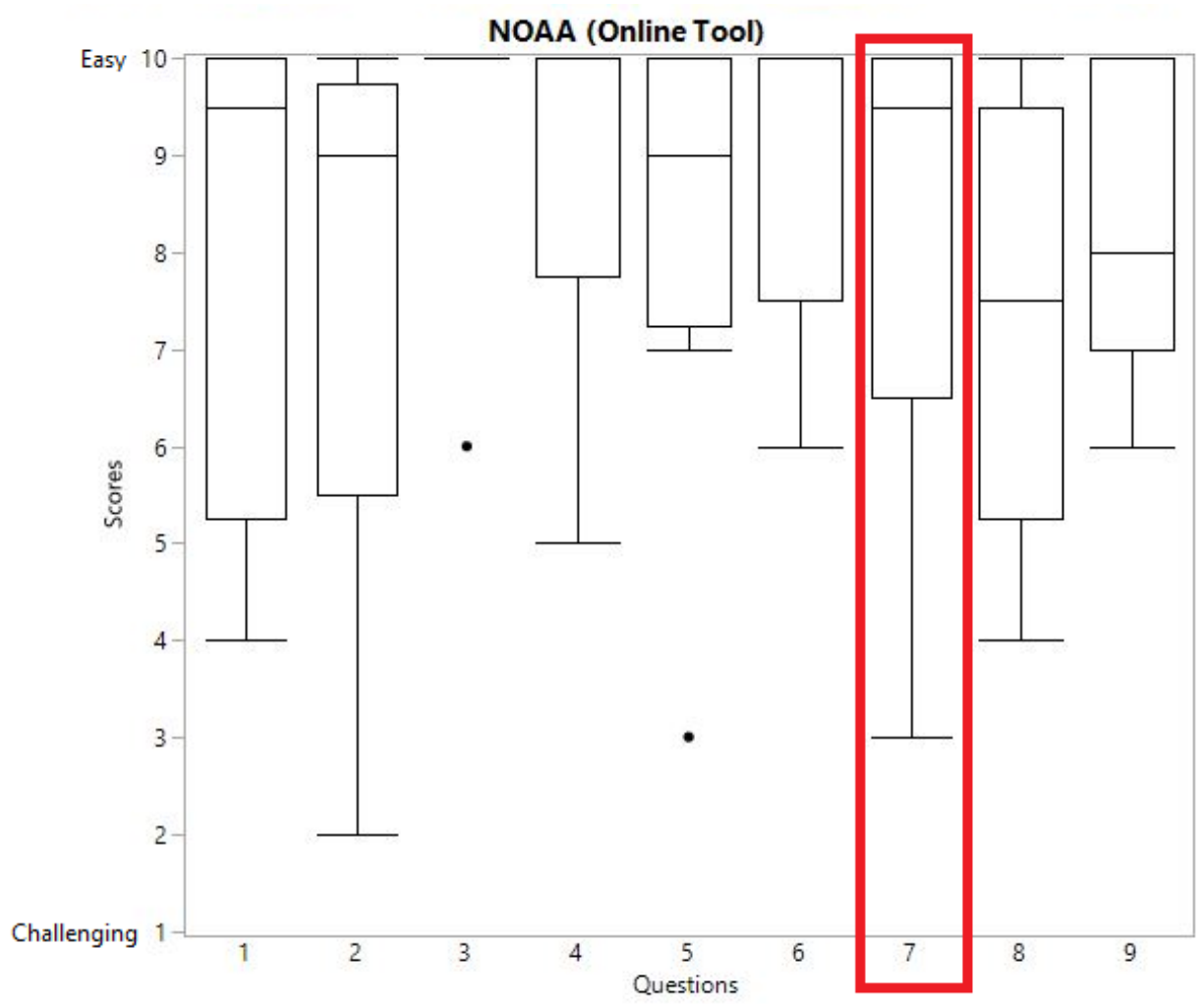

Figure 5.6. Box plots of scores of all eight participants by each question for NOAA Online Tool.

Questions based on usability (1-5) for the online tool showed that most participants indicated usability to be easy to neutral, except for question 2 (On a scale of 1 to 10 how challenging or easy was it to subtract 1979 from 2018?) which had more of a neutral distribution. Questions based on the maps $(6,8,9)$ showed that maps were easy to neutral to interpret and export. Question 6 was specifically focused on map export and showed most participants found it easy to export the map in this tool. While question 8 , map interpretation, showed more of a mixed response between easy and neutral.

Question 7 directly asked participants to score the usability of the program. The above figure showed that most participants found this program easy to use with only a few responses 
weighting toward neutral to use. This was consistent with the results in Figure 5.3, as most participant responses indicated that the NOAA online tool was easy to use.

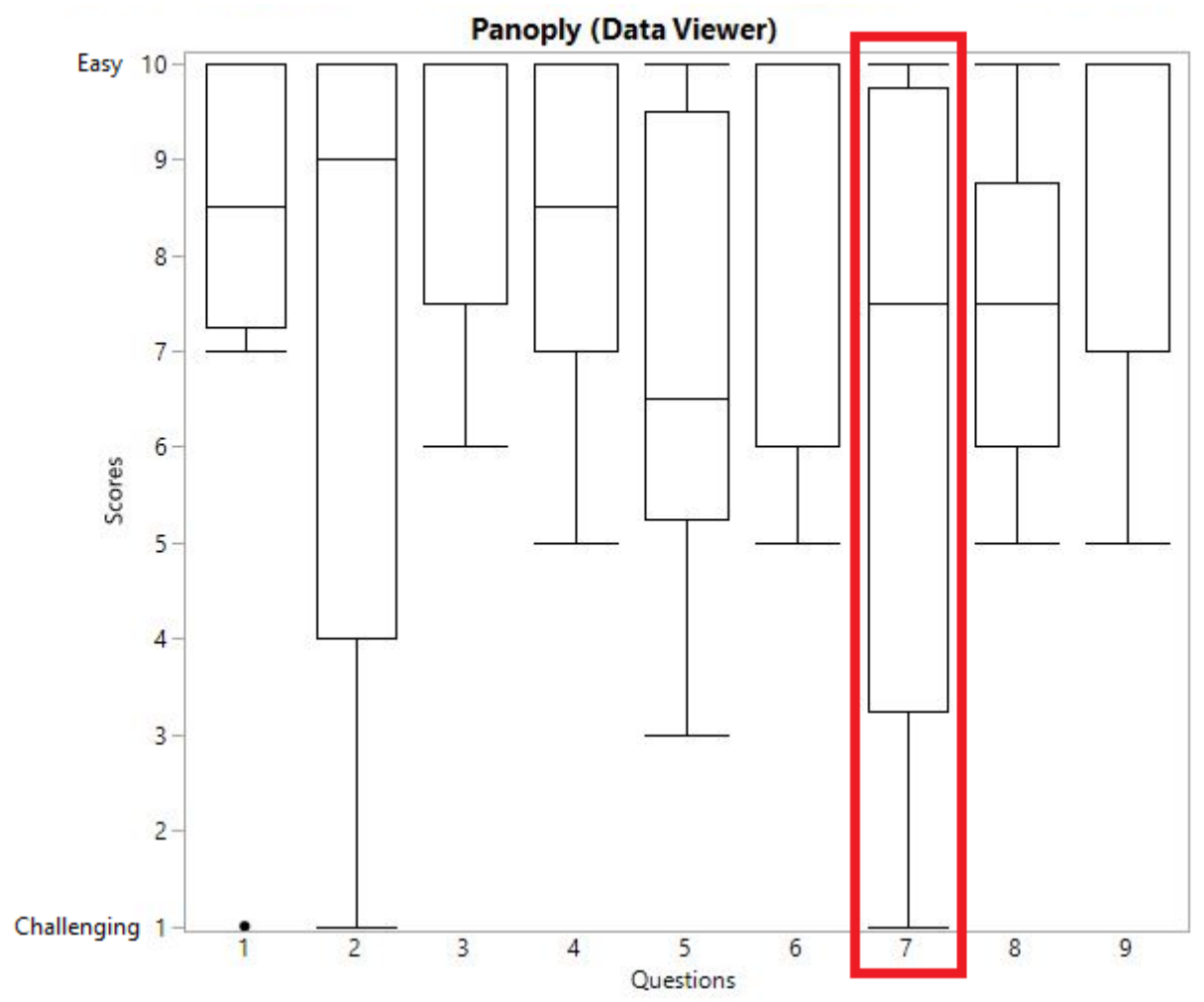

Figure 5.7. Box plots of scores of all eight participants by each question for Panoply.

In the results for Panoply (Figure 5.7), I identified that the first group of question was scored as primarily easy with some neutral. The only exception was in question 2, which was related to generating a map by the subtraction of two months. This program was scored primarily in the easy to neutral range with two questions ( 2 and 7) scoring it as difficult. Figure 5.4 supports this, as individual participant responses corresponded with the above figure. In the third question, the variation of scores of all participants shows the map question as easy to neutral. The responses to the questions stated that exporting the map was easy for most participants as well as it being easy to read the scale bar. There was more of an easy to neutral weighting with question 8 , reading the map, causing it to be considered a mixed rating among participants. 
In the second question group (question 7), participants scored the usability of Panoply as in-between easy and neutral, with a full range of answers from easy to challenging. Based on the raw data values, five participants rated the program as easy to use. This range of values is discussed further in the discussion section.

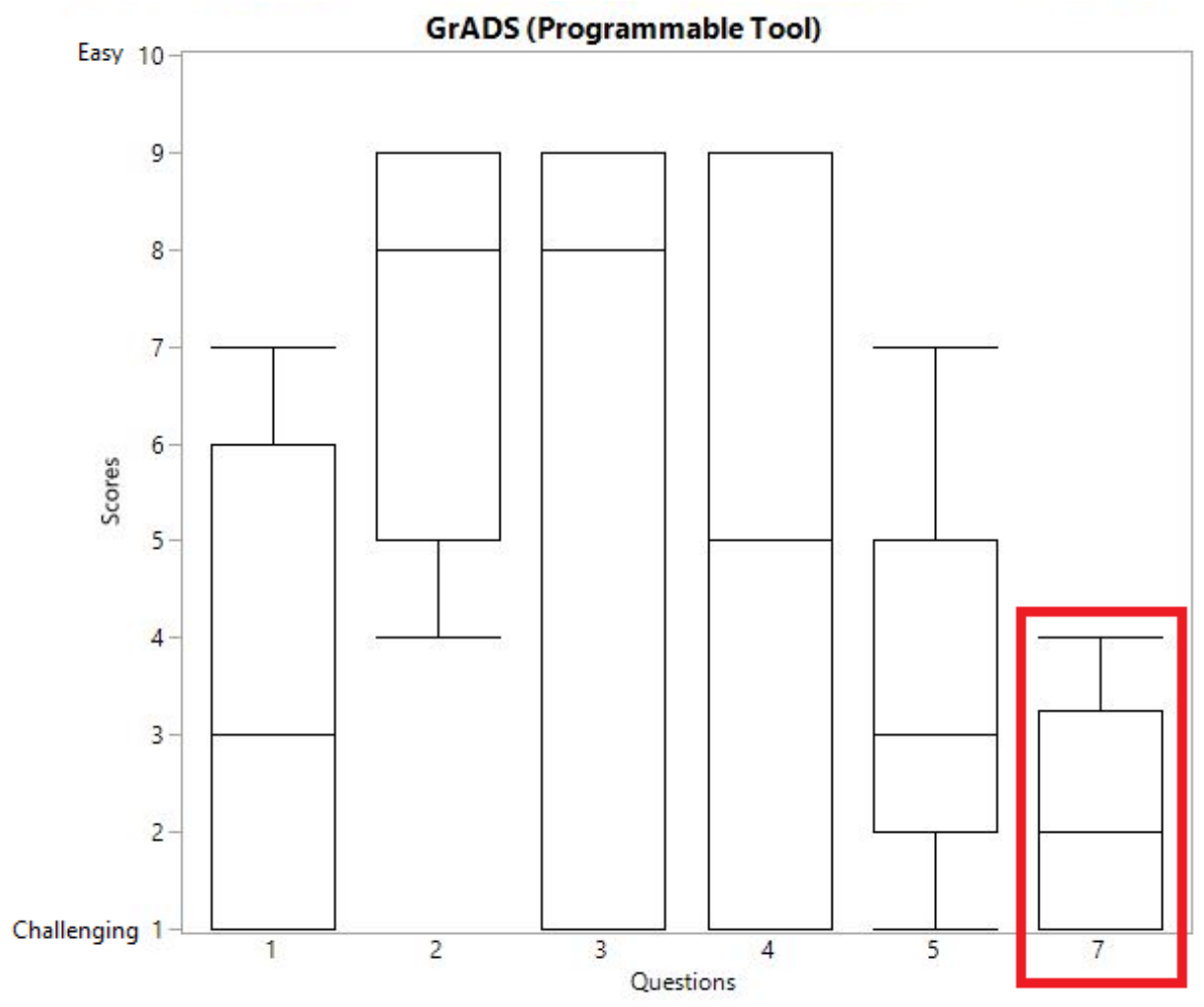

Figure 5.8. Box plots of scores of all eight participants by each question for GrADS.

The GrADS Programmable Tool did not contain the third question group, questions 6, 8 and 9. I have chosen to leave these questions out of the GrADS analysis, because no participants were able to produce a map from this program. Also, participant six was not included due to not giving a response to the questions for GrADS. In the first group of questions, participants responded that this program was challenging to use. The exception here was for question 2 , where participants said it was mostly neutral and somewhat easy to subtract the two months within the code. Questions 3 and 4 also showed an interesting result as both range from somewhat easy to challenging. Question 3 had the highest median, but participants provided a 
wide range of answers. While question 4 had a mid-level median, the raw data confirmed that participant answers were evenly distributed between somewhat easy to neutral and neutral to challenging.

In the second group, participants found the usability of GrADS to be somewhat challenging to challenging. Some results for GrADS contained missing values and this is discussed later.

\subsection{Parametric and non-parametric statistics}

This section presents the results from statistical test preformed in JMP (Tables 5.1, 5.2 and 5.3). The results shown in the first column of tables were from the ANOVA test. The parametric ANOVA was determined by testing the null hypothesis, which assumes the programs usability was not statistically different between the three programs. Next on each table is from the non-parametric Wilcoxon test to identify the $p$-value in relation to the ranking system for each program. The last three columns in each table were the $p$-values for the parametric TukeyKramer test. This test compared each program to each other and determined the $p$-value based on the null hypothesis. 
Table 5.1. $P$-values of significance tests of three programs to questions 1-5 (Group 1).

\begin{tabular}{|c|c|c|c|c|c|}
\hline \multirow[t]{2}{*}{ Question } & \multirow[t]{2}{*}{ ANOVA } & \multirow[t]{2}{*}{ Wilcoxon } & \multicolumn{3}{|c|}{ Tukey-Kramer } \\
\hline & & & $\begin{array}{c}\text { NOAA vs. } \\
\text { GrADS }\end{array}$ & $\begin{array}{c}\text { Panoply vs. } \\
\text { GrADS }\end{array}$ & $\begin{array}{c}\text { NOAA vs. } \\
\text { Panoply }\end{array}$ \\
\hline 1 & $0.0114 *$ & $0.0151 *$ & $0.0294 *$ & $0.0211^{*}$ & 0.9276 \\
\hline 2 & 0.8752 & 0.5091 & 0.8669 & 0.9368 & 0.9838 \\
\hline 3 & $0.0364 *$ & $0.0111 *$ & $0.0406^{*}$ & 0.0917 & 0.9063 \\
\hline 4 & $0.0154 *$ & $0.0185^{*}$ & $0.0162 *$ & 0.0567 & 0.8128 \\
\hline 5 & $0.0021 * *$ & $0.0069 * *$ & $0.0018 * *$ & $0.0235^{*}$ & 0.4703 \\
\hline \multicolumn{6}{|c|}{ * Significant Level at $95 \%$} \\
\hline \multicolumn{6}{|c|}{ ** Significant Level at $99 \%$} \\
\hline
\end{tabular}

In the results of ANOVA for questions 1, 3, and 4, the means of responded scores among the three programs were significantly different at the 95\% level. Question 5 had a $99 \%$ significance. This means that the null hypothesis of similar usability was not supported across all three programs for these questions. Consistently, the Wilcoxon rank test rejected the null hypothesis at the $95 \%$ level for question 1, 3, and 4, and at the 99\% level for question 5. In order to identify the differences between two programs, a Tukey-Kramer test was performed. For the difference test between the NOAA online tool and GrADS, there was a significant difference at the $95 \%$ level for questions 1, 3, and 4, and at the 99\% level for question 5. Panoply vs GrADS was significantly different at the $95 \%$ level for question 1 and 5 , but there were no significant differences for questions 2, 3, and 4. Due to their similar means of responded scores, no statistical difference was found for all the questions of Group 1 between NOAA vs Panoply. The results from Tukey-Kramer test supported that the program usability of GrADS was significantly more challenging from that of the NOAA online tool, in regards to questions 1, 3, 4 and 5. The task shows GrADS was more challenging than Panoply, in regards to questions 1 and 5. However, the difference of program usability between the online tool and Panoply was statistically insignificant regarding all the five questions. This was also confirmed by the figure below: 


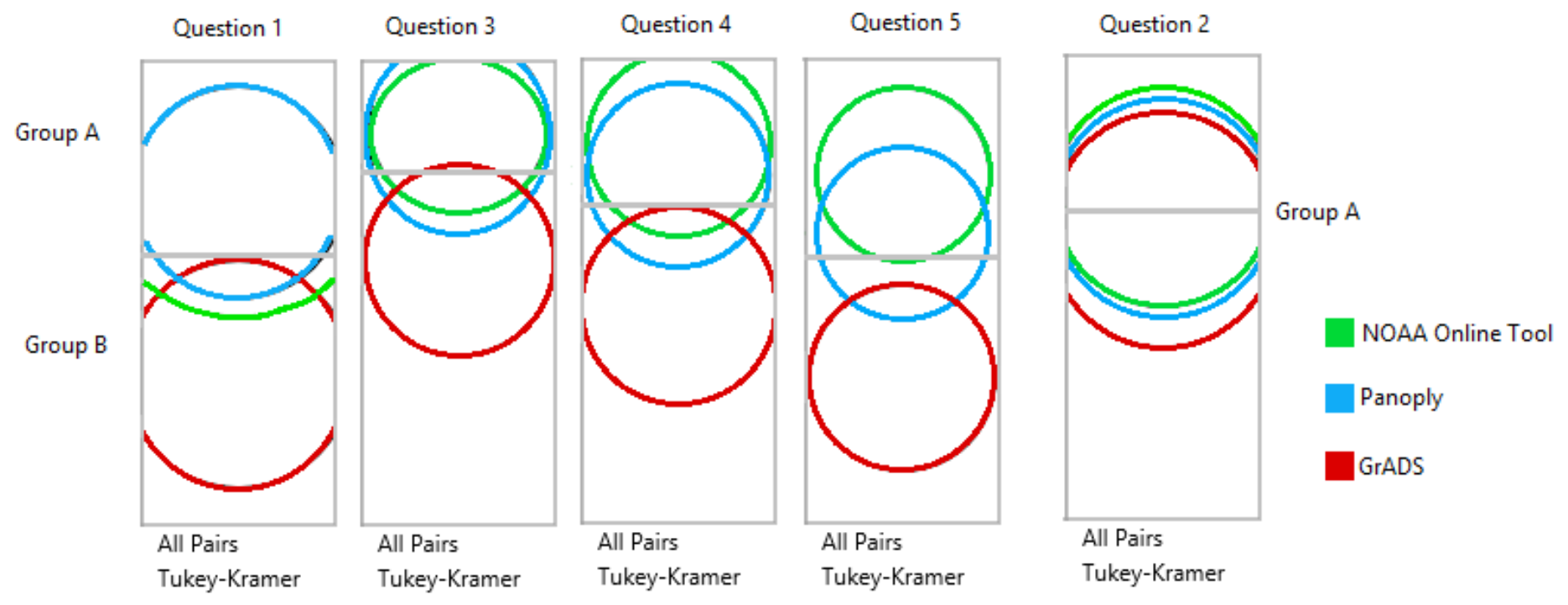

Figure 5.9. Tukey-Kramer test groups are determined by similarity for Group 1 .

This figure shows that for these four questions NOAA and Panoply were similar, placing them into group A, with only some overlap of GrADS. GrADS was dissimilar and was therefore placed into group B. However, Panoply was considered as a part of both groups, based on responses to questions 3 and 4. This means that Panoply, the blue circle, is similar enough to GrADS for these questions. In the question Group 1, there was one question (question 2) that stood out from the rest, because question 2 contained a wider variation of answers as seen in the box plots. Due to that reason the null hypothesis was not rejected in all the parametric and nonparametric statistics, which was also confirmed by the visual inspection of the Tukey-Kramer test (all programs were in group A).

Table 5.2. P-values of significance tests of three programs to question 7 (Group 2).

\begin{tabular}{|c|c|c|c|c|c|}
\hline Question & ANOVA & Wilcoxon & \multicolumn{3}{|c|}{ Tukey-Kramer } \\
\cline { 4 - 6 } & & $\begin{array}{c}\text { NOAA vs. } \\
\text { GrADS }\end{array}$ & $\begin{array}{c}\text { Panoply vs. } \\
\text { GrADS }\end{array}$ & $\begin{array}{c}\text { NOAA vs. } \\
\text { Panoply }\end{array}$ \\
\hline 7 & $0.0016^{* *}$ & $0.0096^{* *}$ & $0.0014 * *$ & $0.0139^{*}$ & 0.5175 \\
\hline \multicolumn{6}{|c|}{$*$ Significant Level at 95\% } \\
\hline
\end{tabular}


Next is Group 2. ANOVA and the Wilcoxon test showed that the null hypothesis was rejected at the 99\% level (Table 5.2). For the Tukey-Kramer tests, the difference of NOAA and GrADS was significant at the 99\% and that of Panoply and GrADS was at the 95\% level. The results supported that the usability of GrADS was significantly more difficult than that of the other programs. However, there was no significant difference in the usability between the NOAA online tool and Panoply. The three programs were split into two groups (A and B) (Figure 5.10). Group A contained NOAA and Panoply, and Group B contained GrADS with little overlap with Panoply, which suggested NOAA is more dissimilar than Panoply from GrADS.

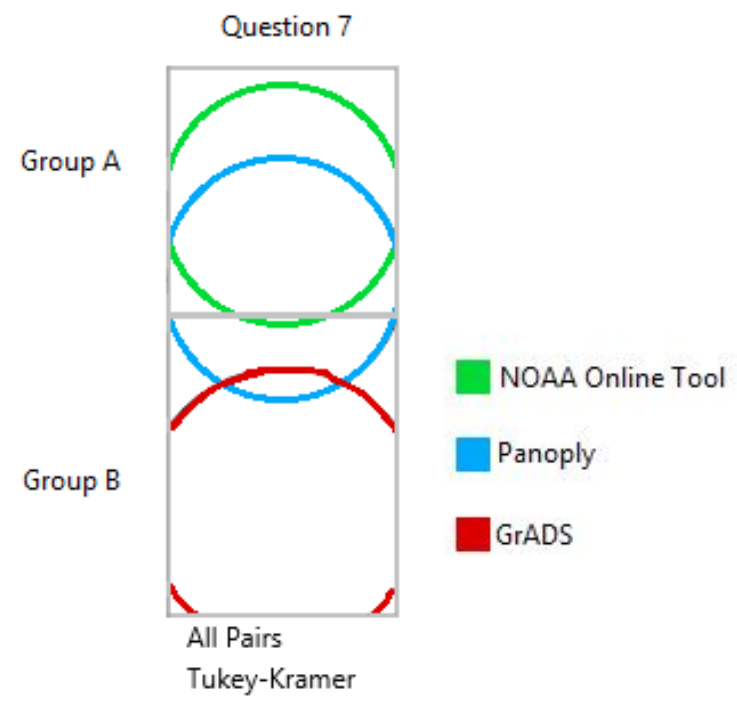

Figure 5.10. Question 7 Tukey-Kramer grouping.

Table 5.3. P-values of significance tests of three programs to the questions 6,8 and 9 (Group 3). GrADS has been omitted from this group, because no participants were able to produce a map.

\begin{tabular}{|r|r|r|r|}
\hline Question & \multicolumn{1}{|l|}{ ANOVA } & \multicolumn{1}{|l|}{ Wilcoxon } & \multicolumn{1}{|c|}{ Tukey-Kramer } \\
\cline { 4 - 5 } & & & NOAA vs. Panoply \\
\hline 6 & 0.708 & 0.8089 & 0.9223 \\
\hline 8 & 0.8089 & 0.9151 & 0.9916 \\
\hline 9 & 0.6658 & 0.6306 & 0.9113 \\
\hline
\end{tabular}


Lastly, the ANOVA (in this case a $t$-test), Wilcoxon test, and the Tukey-Kramer test for Group 3 showed there was no statistically significant difference in the program usability between NOAA and Panoply. The ANOVA and Wilcoxon tests for these questions in Group 3 were different from Groups 1 and 2, since GrADS was not considered. Also, there were only two programs (NOAA and Panoply) were compared in the Tukey-Kramer test, which showed no significant difference between the two programs (Table 5.3). This will be discussed below.

\subsection{Qualitative analysis}

The qualitative results supported my second research question "What are participants' attitudes towards the programs?" Five questions were asked after participants completed the surveys. Qualitative analysis was performed by use of deductive coding. These results were organized by similar topic of question. Discussion of these results takes place in the discussion section.

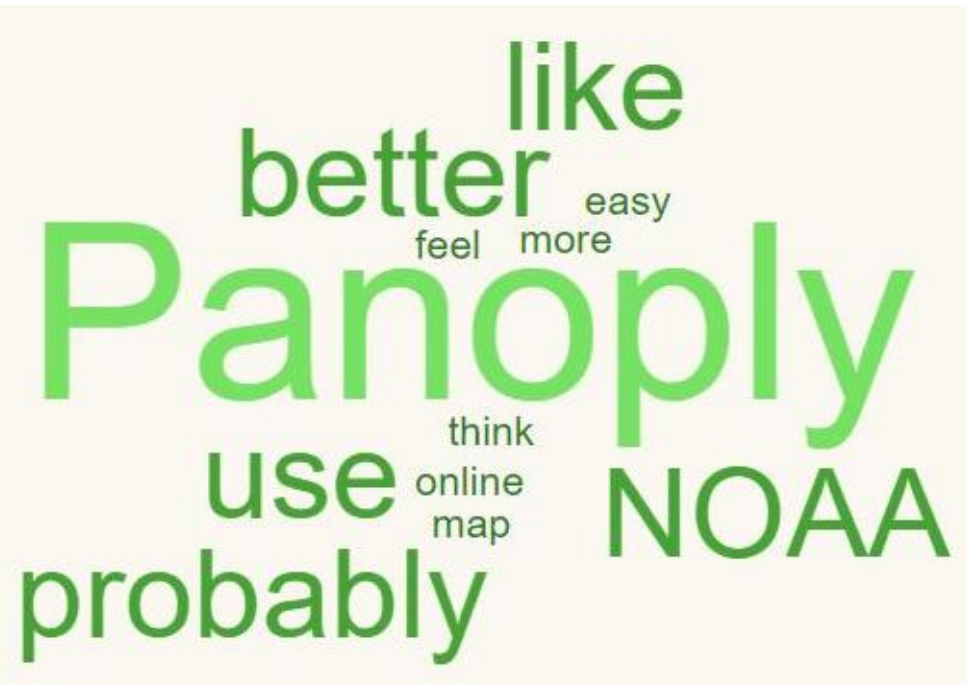

Figure 5.11. Word Cloud based on frequency of word use for question 5 "Which of the programs do you prefer?" 


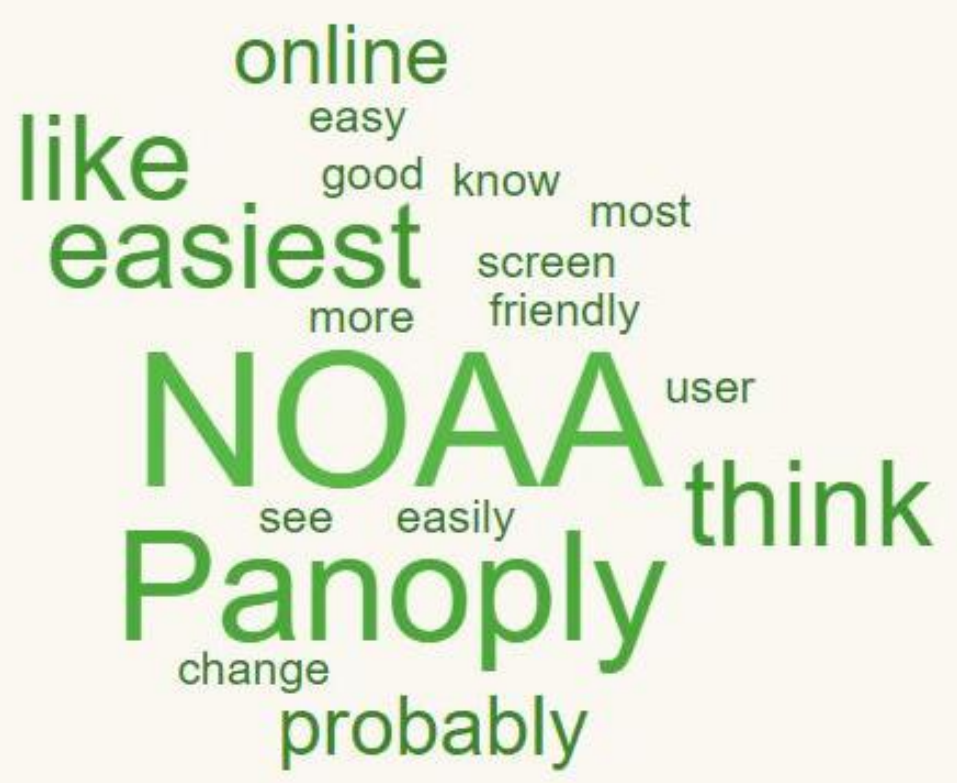

Figure 5.12. Word Cloud based on frequency of word use for question 2 "Which was the easiest to use or best to use?"

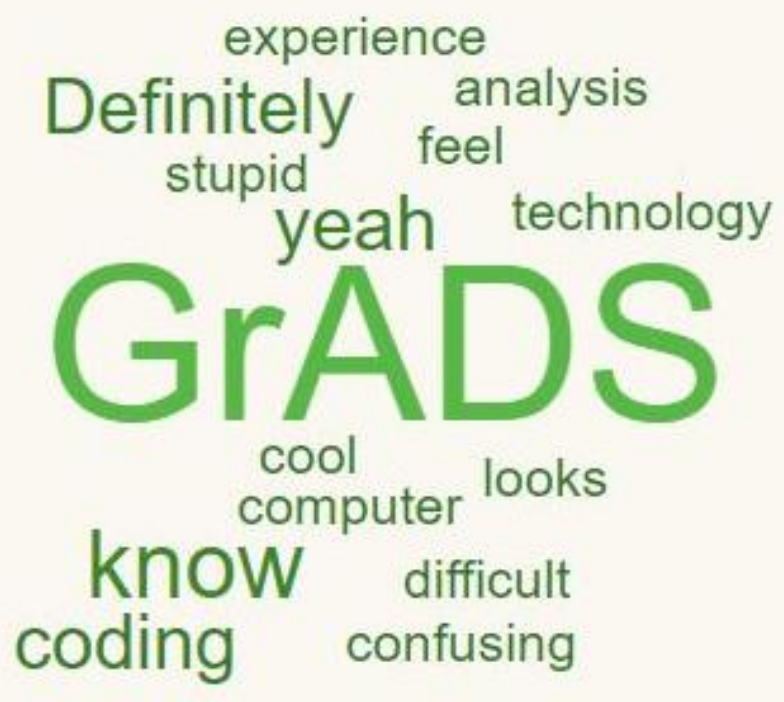

Figure 5.13. Word Cloud based on frequency of word use for question 1 "Which Program did you find to be the most difficult?" 


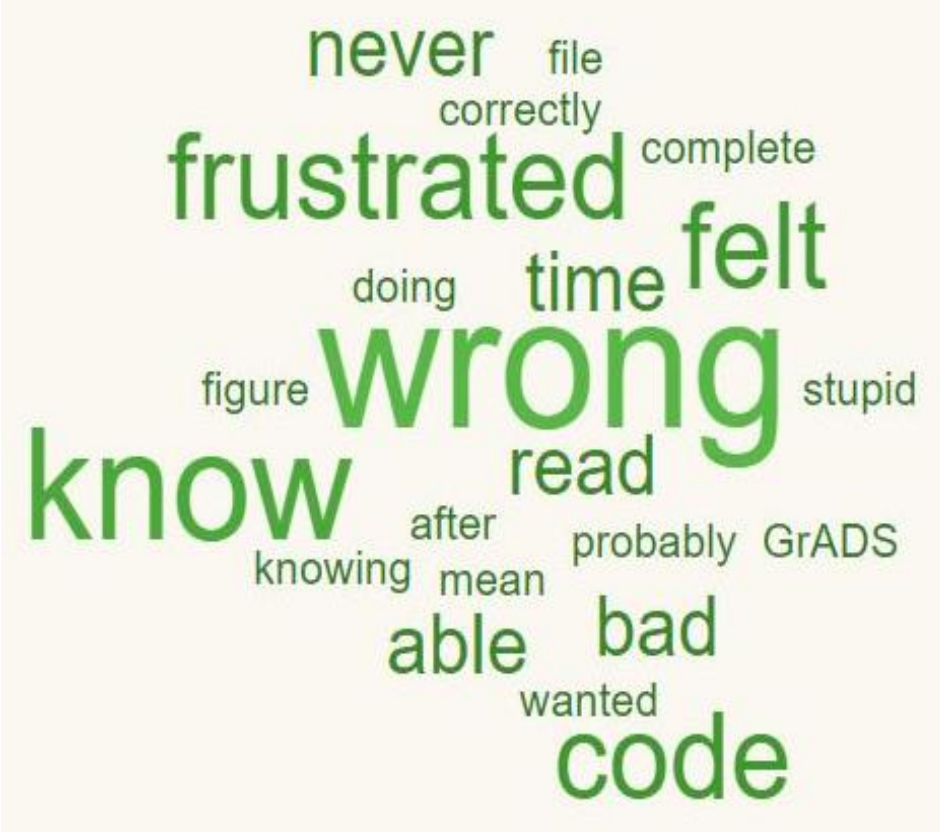

Figure 5.14. Word Cloud based on frequency of word use for question 4 "How did it make you feel when working with the coding?"

First, I analyzed which program participants said they preferred. Figure 5.11 indicated that the program Panoply had the highest frequency of use when answering this question. Participants stated that Panoply was preferred due being aesthetically appealing, more convenient, making more sense, and that it was "10 times better than" the NOAA online tool. However, some participants preferred the NOAA tool because it is easier to use.

Second, I analyzed responses to the question, "Which (program) was the easiest to use or best to use?" The majority of participants said that the NOAA Online Tool was the easiest to use. In Figure 5.12, NOAA had the highest frequency of use along with the terms "easiest," "like," and "online." Participants cited that it was easy to use because the interface was all "...on one page..." and it was "simple." The first two word clouds raised an important question: Why do participants prefer to use Panoply, but find NOAA to be the easiest? This was well represented by the following statement from a participant:

“...probably Panoply just because I think it produces a better map in the end result, NOAA's easier 
to use but I think if you want to actually make a more

readily understood map the Panoply would be the one

to use, so, I liked it the best."

This will be discussed below in the discussion section. After knowing what programs were easy to use or the participants prefer to use, it is important to understand how participants view the difficulty of the three programs. Participants were asked "Which Program did you find to be the most difficult?" all eight responded they found GrADS to be the most difficult program to use. Several of the participants said the reason for this was due to interaction with coding in the programmable tool. In Figure 5.13, GrADS was centered and was the largest word. Participants also stated that the program was "confusing," "difficult," with a few even mentioning that it made them feel "stupid." When asked why they felt this way, one participant responded:

\author{
"I don't know, I guess if like I was like given \\ everything to type in I probably could have gotten it \\ but like the fact that I don't know how to personally \\ code. So, like I don't know what like how sensitive it is \\ made, it's difficult but like the other ones were easy \\ you just plug it in and you got it".
}

This quote emphasized the next point made by participants, which was that most commented on increased difficulty as a result of not knowing how to code. When participants were asked, "How did it make you feel when working with the coding?" three responded that it made them feel frustrated. This was due to not being able to produce a map, as well as receiving error messages from GrADS. Other participants said it made them feel stupid or irritated. One participant even said, "I felt kinda smart but then I couldn't get, so then it went away." These feelings can also be seen in Figure 5.14. A term that has the highest frequency in this question is "wrong." Participants felt they were doing things wrong or they were unsure of why something was wrong. Also, the word know shows a high frequency of use. This is related to the phrase "I don't know," which was said by several participants in this question. 


\subsection{Non-participant observation}

On average most participants were able to complete the NOAA Online Tool section in 10-15 minutes. Only one participant did not complete the NOAA map correctly due to a mistake in the subtraction process. Panoply took participants roughly 20 minutes to complete. Five participants did not correctly complete the map. Three participants were unable to properly execute the subtraction step. While two participants completed all other stages correctly, they did not complete the latitude and longitude step properly, and both of these maps were centered over the north eastern tropical Pacific Ocean, not over the United States. Participants worked with GrADS for roughly one hour. At the one-hour mark I had to tell most participants that it was okay to move on without producing a map for this program. Six of the eight participants did so quickly, while two participants chose to continue working on GrADS for an additional 20-30 minutes.

GrADS was the program that participants spent the most time interacting with during the two-hour long focus groups. As noted above, I observed their body language and other forms of non-verbal communication of participants while they interacted with GrADS. Signs of irritation and frustration were common among participants. Participants would place their arm in front of them on the desk and/ or cross their arms or legs, in combination with their facial expression; these are both forms of subconsciously blocking oneself (Vaughan, 1982). Two participants expressed a non-verbal sigh of frustration when given error messages by GrADS. Some participants even made facial expressions while working with GrADS. The two most notable types of facial expression among participants were either pursed lips and narrowed eyes or looks of absolute confusion. One participant even showed signs of discomfort when first seeing the script code by leaning back, away from the computer. The participant later stated that they felt "very scared" when they saw the code. Unlike GrADS the other two programs, NOAA and Panoply, showed minimal body language change for participants. Participants had an open body language when working with both programs, and only expressed minor confusion. This suggested that participants found NOAA and Panoply relatively easier to work with then GrADS. 


\section{Discussion}

This section begins with a discussion of the results from survey question 2 , "On a scale of 1 to 10 how challenging or easy was it to subtract 1979 from 2018?" It then presents findings from the qualitative analysis on usability versus preference of the different programs. Next, it discusses the usability of each program based on the quantitative and qualitative results. This is followed by a discussion on the limitations of this research.

\section{Survey question 2}

One of the most interesting results seen in the quantitative analysis was in the participant responses to question 2. This question asked, "On a scale of 1 to 10 how challenging or easy was it to subtract 1979 from 2018?" The results showed that the scores to this question differed from all others in Group 1 by having accepted the null hypothesis in the ANOVA and Wilcoxon tests, which represented the programs usability was not statistically different between the three programs. It could also be seen in the Tukey test where there was no clear separation among the three programs.

Upon further visual inspection, participants scored question 2 with a wider range of answers for NOAA and Panoply than for GrADS. This can also be seen in Figures 5.6 and 5.7, where the range was wider for question 2. This raised the question: why did participants find GrADS similar to the other programs regarding this usability question? After consulting the raw data values, I was able to confirm that GrADS did not contain lower values from each individual participant, but the average score for this question was a 6.88 out of 10 . This means students found that subtracting January of 1979 from January 2018 was somewhat easy or neutral. Further investigation into Panoply showed that question 2 had an average score of 7.38 out of 10, giving this program a higher average than that of GrADS. NOAA had an average score of 7.63 out of 10, also giving this program a higher average than GrADS. These results were consistent with all other questions in Group 1, which indicated that GrADS is more difficult to use. However, in the case of question 2, the difference of averaged scores between GrADS and two other programs were less than one point, which was not statistically different. In addition, GrADS did not contain any values lower than 4, but NOAA contained one value of 2 and Panoply contained one value of 3 and one value of 1 . Meaning that some participants did find GrADS easier to use than 
Panoply or NOAA. GrADS contained 4 easy values while both NOAA and Panoply contained 5 easy values each. The only major difference here was that GrADS contained no values of 10, but both NOAA (2 values) and Panoply (3 values) did. These results show conflicting opinions from participants on the overall use of this usability question.

The raw data indicates somewhat surprising results that no participant rated GrADS for this question as being challenging, but two participants for Panoply and one participant for NOAA did score this question as challenging. Even though these results could be seen from the visual inspection, it was very interesting to find that one participant scored challenging on question 2 for both NOAA and Panoply, but then scored GrADS as neutral. There was no clear answer as to why participants would find GrADS as similar to Panoply or NOAA when this was not the case for all other questions. This is a potential area for further study about usability of the programs to confirm the results from this study with those based on a larger group of participants.

\section{Usability versus Preference}

The qualitative analysis revealed an interesting result with a comparison of questions 5 and 2. Question 5 asked participants "Which of the programs do you prefer?" and question 2 asked participants "Which (program) was the easiest to use or best to use?" Participants responded that they would prefer to use Panoply but found NOAA easier to use. This is interesting because they chose two different programs. I would have assumed that the program that students found easiest is the one that they would prefer to use. Some of the reasoning from the participants given for their preference for Panoply were:

"Panoply that's what it was, that one seemed like more of a professional looking it seemed more professional than the NOAA one, but I could also see using it personally"

“The panoply, its hard but it's like once you figure it out you understand it a little bit better, I feel like it would be 10 times better than um (the online tool) yeah, it would look better you know" 
Both of these participants chose Panoply over the NOAA tool because of the graphical output and the majority of participants agreed with this. The quote in the results section even directly said that the Panoply would be better because of the map. This was the primary reason given by students.

Some participants found the NOAA tool to be easier. A few participants responded that the NOAA tool was easier to use due the following reasons.

"Um probably the online one (NOAA) it was all on one page and you can easily see all the things you would like to change."

"It (NOAA) was easy very simple I liked it better."

"NOAA just because you only have to go to one page you're just on one screen and you plug in all the info and then even though it was annoying in this updated version to scroll down to your end result doing everything on, never having to change your screen I think makes it the easiest rather than transferring files and having to edit things yourself I would definitely say that's the most user friendly of them all"

Participants liked that the online tool was all on one page instead of having multiple tabs to work with. It was just easier to have everything in a central location that did not require using multiple screens. There were varying reasons between participants where one participant said NOAA was "simple", but Panoply was "10 times better". It seemed to reason that participants like that NOAA was all on one page, but did not like the map output, while participants prefer to use Panoply, which contained multiple tabs, because of its map output. Therefore, students are sophisticated enough to recognize that easy is not always best if the results are worthwhile. This is a direction for future study, either by conducting more surveys or by designing a new study that specifically explores the preference of graphical output versus participant interaction with each program's interface. 


\section{The three climate programs}

\section{NOAA online tool}

Both the quantitative and qualitative results supported the expectation that NOAA was the easiest tool to use for participants. This program's main attributes were being an online tool, and the interface all being located on one page. Participants scored NOAA as easy to use for Group 2 questions in the quantitative results. This was then validated qualitatively when participants were interviewed and responded that NOAA was the easiest to use. One minor issue was the output map not showing up at the top of the web page after creating the plot. Several participants mentioned this issue and ended up spending more time working with the NOAA tool, because they could not find the map. This tool needed to go back to its previous design when the map output appeared at the top of the web page. This might cause some confusion for undergraduate students working with the online tool for the first time. Results indicated that NOAA was a valuable program to introduce undergraduate students to climate science. This program could provide an easy way to interact with climate data for students who have never done so. This tool could also help to develop and build students climate science literacy.

\section{Panoply data viewer}

This program was chosen by participants as the most preferred program over the NOAA tool because of how aesthetically pleasing its output is. Panoply contains multiple tabs and can process multiple datasets at a time. In the quantitative analysis, participants scored Panoply as easy to neutral to use but found that it was challenging in some respects. The responses given in the qualitative results supported these results from the quantitative analysis. However, participants reported that even while Panoply could be hard to use, they would prefer it due to the output, with one participant saying they would use it for their own research.

The expected result for Panoply was that it would be considered as a user-friendly tool and that participants would find it relatively easy to use with only some difficulty. An unexpected result was that participants' main reason for their preference of Panoply is the map it creates. As such, I argue that Panoply is a valuable tool for undergraduate students to learn to use 
climate data. This tool could increase students' climate science literacy by providing a data viewer for them to interact with climate datasets.

\section{GrADS programmable tool.}

GrADS was determined by participants to be the most challenging and difficult program of the three programs in this research. Participants found it to be confusing and also stated the biggest problem with GrADS was the use of coding. One participant gave this negative response: "...And then the last one (GrADS) I don't have any words for that one". It was common for participants to exhibit frustration with this program. Beyond the frustration, participants also felt they were not educationally ready to handle GrADS. One participant said:

"As I kind of answered in my packet I think the problem with grads is that someone needs an extensive mastery of being able to read a code knowing what all the fine-tuned traits of it all are and knowing that oh this spacings wrong or this is wrong and I don't have that so definitely is what made it more difficult"

Other participants did not like GrADS. Because this program made them feel unintelligent, and they were not able to complete the map output. Participants did not expect the difficulty level of GrADS. "I just did not like GrADS, I didn't realize it was going to be that hard I thought I was like stupid I couldn't figure it out, but I was like.” One participant even repeatedly stated while working on the survey "I hate GrADS." GrADS was the only program that caused emotional responses of frustration, irritation, and feelings about lack of intelligence. One participant also said that they initially felt smart when first working with GrADS, but once the code stopped working they began to feel "stupid." These emotional responses need to be taken into consideration when introducing this program to students.

An advanced statistical program such as GrADS is an important tool that needs to be taught for the advanced data analysis in climate science, but the feedback of participants who said that mastery is needed should be considered in teaching. If participants are properly trained to use GrADS, they would be able to overcome many of the obstacles they faced during this project. Thus, GrADS is not a readily usable program for those just starting in climate science. 
Training is required to be able to understand and interact with GrADS. I elaborate on this recommendation in the conclusion.

\section{Limitations}

This study faced many limitations. In my proposal I said, “...Limitations of this research as a whole are yet to be determined." I originally thought my only problem was going to be the size of the computer room, which was never even an issue. I could not have anticipated the many limitations I faced in reality.

My biggest limitation in this research was recruitment. I began with the goal of conducting 3 focus groups with 15 participants each, in addition to 15 interviews on dataset accessibility. These were the hopes of a bright-eyed masters student. In the end, I was able to conduct 5 focus groups with a total of 8 participants. Several people volunteered for this research, but only about 1 in 3 students who volunteered actually attended the focus groups. Only three volunteers were willing to participate in additional research on dataset accessibility, which had the same average attendance as the focus groups, only one participate completed the interview, making this an area to pursue as future study.

I tried several strategies to spark interest in volunteering for my research. The first attempt I made at recruitment was in Spring 2018. I received permission to email undergraduate students in my department to gain volunteers, but only had two participants show up for my efforts. After going back to the drawing board with my committee, I offered a gift card raffle as an incentive for students to participate. This did help me attract the remaining 6 participants for my research in Fall of 2018. I also hung flyers around Brooks Hall and spoke in front of many classes. Several professors in the department graciously agreed to advertise my focus group dates. Even so, recruitment remained low. This is likely because I was asking too much time of undergraduate students and could not give them extra credit for their efforts, due to IRB constraints. I believed that an hour and half was a reasonable amount of time to ask of volunteers, but perhaps that was not reasonable to others. Some perspective volunteers told me they really wanted to participate but could not because of work and class obligations. 
I had some other limitations too, including the very short amount of time in which to conduct my analysis, because of the recruitment difficulties. Another limitation of this research has to do with computer issues. The computer lab in which I conducted my research went through a university mandated update to transfer systems from the original local network with class common drives to the university system. Common drives were unable to be accessed because of this reason. Luckily my advisor had an independent server in his lab that could be remotely accessed by other computers in the building allowing for the set-up of a class style account. This change to the department computers also required me to update my lab manual instructions from their original version to accommodate for the new file paths, user information, and data locations. While at times frustrating, these limitations taught me about the realistic challenges faced by many researchers and will inform my future efforts to design research projects.

\section{Conclusions and Implications}

The aims of this research were to address the two research questions: 1) How usable are climate-based programs to undergraduate college students? 2) What are student's attitudes toward these programs, specifically the most difficult program chosen by the participants? Through this research I was able to investigate these questions and address them.

To investigate the first research question, I applied quantitative methods. Participants found the NOAA online tool and Panoply data viewer were relatively easier to work with than GrADS programmable tool. The statistical results showed that NOAA was the highest in usability among the three programs. Panoply data viewer was the next usable program, but it was not statistically different in usability from the NOAA program. However, the usability of GrADS was significantly different from that of NOAA and Panoply for all the survey questions, except for question 2. For instance, GrADS program was very difficult for participants to use and participants never achieved a map output during the focus groups. The main limitations in the usability of GrADS was the lack of map output and the majority of participants being unfamiliar with coding. The results from the quantitative analyses suggested that under time constraints and with little or no prior training, GrADS was not readily usable for undergraduate college students. 
My second question was investigated with qualitative methods. The qualitative results identified Panoply as most preferred program to use, NOAA as the easiest program to use, and GrADS as the most difficult program to use. Participants preferred Panoply because of the ability to make aesthetically pleasing maps and the option with multiple parameters. NOAA was identified as the easiest tool for participants to use because it took a short amount of time to complete the tasks and the interface was located on one page versus having multiple tabs. GrADS was the most difficult because of the need to use coding which caused a negative emotional response in some participants. This emotional response was identified by the participants' body language observed in non-participant observation, as well as through semistructured interview responses. While participants clearly felt frustrated when working with GrADS, neither of the other programs caused a strong emotional response of any kind.

The results from the quantitative and qualitative analysis agreed with my hypothesis that participants would find Panoply and NOAA easy to use as compared to GrADS. The only difference was that whereas I hypothesized that Panoply would be considered the most userfriendly tool, in actuality participants felt “...I would definitely say that's (NOAA online tool) the most user friendly of them all". I hypothesized that GrADS would be the most difficult tool for participants to use, based on personal experience, which was confirmed based on the quantitative and qualitative results. I also hypothesized that no participant would be able to produce a map in GrADS. While I hoped to be disproven, this hypothesis was also confirmed.

After having conducted this research, I recommend instructors use each program in teaching at specific stages. Based on the quantitative and qualitative results with Panoply as the most preferred program and NOAA as the most usable program, I suggest Panoply to be used as an introductory program to create an easy entry point for students to understand and work with climate data. This program allows students to think about what they are doing and gives them more information to work with. Being able to change and set multiple options is important to enhancing their climate science literacy. Students will be able to produce appealing maps to use in their own research.

The NOAA online tool can be beneficial due to its higher level of usability among the three programs. It can also be used to teach students about climate data analysis because of the online available interfaces that allows for access to data without having to download anything, 
allowing users to easily choose a dataset and set options to make a map. The only drawback with this program is the map output, which might be aesthetically less preferred to users compared to Panoply.

GrADS programmable should be taught to more advanced students after some training and more time should be given to learn it than the other programs. A good place to start with this tool is with a sample code to teach students who have never used or seen coding before. For example, this code could include a self-describing file code (sdfopen) where there is no destination designator file $(d d f)$ required. Participants' most common mistake in this survey study was calling the wrong dataset through $d d f$. That means climate data other than NARR, which can be directly opened via sdfopen, would be beneficial to be used for this teaching purpose. Once students become more comfortable with the GrADS script they can start introducing $d d f$ and other more complex commands. Once students are trained in GrADS, it helps to increase their climate literacy and provide an avenue for advanced knowledge in climate science.

The remaining question is whether or not identifying the usability of these programs can improve the climate science literacy for undergraduate college students. It is necessary to conduct further research with more participants to address how the programs usability could affect climate science literacy. Findings from this study suggest that the different programs' usability could affect the learning outcomes of undergraduate college students and thereby contribute to the advancement of their climate science literacy. Further study with a larger sample size is needed to confirm the results from this research. I would recommend separating each program into individual sections and only evaluating one program during each focus group. Finally, more research is needed on undergraduate college students' accessibility of climate datasets. This could help address concerns of credibility and mistrust students have of the scientific and academic communities.

\section{Personal reflection}

For me, this was a difficult study. I learned that nothing goes as planned. You have to be able to adapt and keep moving toward your goals. Even when things seem like they are not working, you must find a way to get back on track. I felt at times that I would never get enough 
participants to complete my research. But I also had a wonderful support system all around me, cheering me on every step of the way. There was a committee member always there to help piece things back together, and I could not have done this without them. I had to let go of parts of this project that I was originally so excited about. In the end, that gave me more time to focus on the results I could achieve. It was scary and amazing to conduct a focus group on my own for the first time in my academic career. This research project taught me a lot, showed me how to create balance in my life, and how to achieve my goals.

Interacting with participants was something I was not use to. It was interesting to observe them as they worked on each program. Especially when participants were working on GrADS. I would often smile as they made mistakes, because I had made those same mistakes when I was learning the program. I could relate to how they were feeling.

All of the hours spent organizing my thoughts, creating the survey, and forming questions were well worth the end result. As difficult as this research was, I know that I am better for having experienced it. When this project first started, I was determined to add something to the field of climate science literacy. At the end, I can say with honesty I have accomplished my goal. 


\section{References}

Bedford, D. (2015). Does Climate Literacy Matter? A Case Study of US Students' Level of Concern about Anthropogenic Global Warming. Journal of Geography, 115(5), 187-197.

Caretta, M. A., Sanders, J., Turley, B., Williams, A. R., Guillen, L. A., \& Zegre, N. P. (under review) Does university students socioeconomic background shape their perception and attitude towards climate change? A pilot study from Central Appalachia, USA. Research in Science Education

Chang, C. (2015). Teaching climate change - a fad or a necessity? International Research in Geographical and Environmental Education, 24(3), 181-183.

Clark, V. L., Creswell, J. W., Green, D. O., \& Shope, R. J. (2008). Mixing Quantitative and Qualitative Approaches. An Introduction to Emergent Mixed Methods Research. In Handbook of Emergent Methods (pp. 363-387). Guilford Press.

Clifford, N. J., Cope, M., Gillespie, T. W., \& French, S. (2016). Key Methods in Geography. Los Angeles: SAGE

Cohen, D., \& Crabtree, B. (2006). Semi-structure interviews. Retrieved October 12, 2017, from http://www.qualres.org/index.html

Cooper, J., Lewis, R., \& Urquhart, C. (2004). Using participant or non-participant observation to explain information behaviour. Information Research, 1-15.

Creswell, J. W., \&, Clark P. (2007). Designing and conducting mixed methods research (3 ${ }^{\text {rd }}$ ed). Los Angeles: SAGE.

Cuncic, A., \& Gans, S. (2018). 10 Best and Worst Small Talk Topics. VeryWell. Retrieved from https://www.verywellmind.com/small-talk-topics-3024421

Denham, M. A., \& Onwuegbuzie, A. J. (2013). Beyond Words: Using Nonverbal Communication Data in Research to Enhance Thick Description and Interpretation. International Journal of Qualitative Methods, 12(1), 670-696.

Dupigny-Giroux, L. L. (2010). Exploring the Challenges of Climate Science Literacy: Lessons from Students, Teachers and Lifelong Learners. Geography Compass,4(9), 1203-1217.

England, K. V. (1994). Getting Personal: Reflexivity, Positionality, and Feminist Research*. The Professional Geographer, 46(1), 80-89.

Field, A. P., Miles, J., \& Field, Z. (2012). Discovering statistics using R. SAGE Publications.

Flaim, A., \& Speckart, J. (2016, November 01). What is a Code?: Qualitative Research Methods. Mod•U: Powerful Concepts in Social Science,.Retrieved 2018, from https://www.youtube.com/watch?v=BAKRKZq_Ebo

Fonteyn, M. E., Kuipers, B., and Grobe, S. J. (1993). A description of think aloud method and protocol analysis. Qualitative Health Research, 3(4), 430-441.

Gill, P., Stewart, K., Treasure, E., \& Chadwick, B. (2008). Methods of data collection in qualitative research: Interviews and focus groups. British Dental Journal, 204(6), 291295. 
"Grid Analysis and Display System (GrADS)." GrADS Documentation. George Mason University, n.d. Web. Feb. 2017.

Guo, F. (June 2014). A Road Map for 21st Century Geography Education: Geography Education Research. Journal of Research and Didactics in Geography, 1(3), 81-86.

Harmon, A. (2017, June 12). Climate Science Meets a Stubborn Obstacle: Students. New York Times. Retrieved September 21, 2017, from https://nyti.ms/2sFhOTI.

Harrington, J. (2008). Misconceptions: Barriers to Improved Climate Literacy. Physical Geography,29(6), 575-584. doi:10.2747/0272-3646.29.6.575

Hayter, A. J. (1984). A Proof of the Conjecture that the Tukey-Kramer Multiple Comparisons Procedure is Conservative. The Annals of Statistics, 12(1), 61-75.

Johnson, R. B., \& Onwuegbuzie, A. J. (2004). Mixed Methods Research: A Research Paradigm Whose Time Has Come. Educational Researcher, 33(7), 14-26.

Leavy, P. (2017). Research Design: Quantitative, Qualitative, Mixed Methods, Arts-Based, and Community-Based Participatory Research Approaches. New York, NY: Guilford Press.

Lem, P. (2016). Inside W.Va.'s battle over teaching climate change. E\&E News. Retrieved October 25, 2016, from http://www.eenews.net/stories/1060036453.

Lemke, K. A., \& Ritter, M. E. (2000). Virtual Geographies and the Use of the Internet for Learning and Teaching Geography in Higher Education. Journal of Geography in Higher Education, 24(1), 87-91.

McCaffrey, M. S., \& Buhr, S. M. (2008). Clarifying Climate Confusion: Addressing Systemic Holes, Cognitive Gaps, and Misconceptions Through Climate Literacy. Physical Geography, 29(6), 512-528

McGrew, J. C., Lembo, A. J., \& Monroe, C. B. (2014). An introduction to statistical problem solving in geography. Long Grove, Ill: Waveland Press.

Mesinger, F., et al. (2006), North American regional reanalysis, Bulletin of the American Meteorological Society, 87(3), 343-360.

Miléŕ, T., \& Sládek, P. (2011). The climate literacy challenge. Procedia-Social and Behavioral Sciences, 12, 150-156.

Moore, D. S., \& McCabe, G. P. (1999). Introduction to the Practice of Statistics (3rd ed.). New York: W.H. Freeman.

National Aeronautics and Space Administration Goddard Institute for Space Studies. (2017). Panoply. Retrieved October 05, 2017, from https://www.giss.nasa.gov/tools/panoply/version1.html

National Centers for Environmental Prediction, Earth Systems Research Laboratory Web. "North American Regional Reanalysis." Retrieved 11 July 2016, from https://www.esrl.noaa.gov/psd/data/gridded/data.narr.monolevel.html

National Center for Education Statistics. (2018). The NCES Fast Facts Tool provides quick answers to many education questions. Retrieved from https://nces.ed.gov/fastfacts/display.asp?id=372

National Center for Science Education. (2012). Recommendations from the Climate and Energy Literacy Summit (pp. 3-17, Rep.). Berkley, CA: Berkley. 
National Oceanic and Atmospheric Administration. (2018). ESRL. Physical Sciences Division. Monthly/Seasonal Climate Composites. Retrieved October 05, 2017, from https://www.esrl.noaa.gov/psd/cgi-bin/data/composites/printpage.pl

National Oceanic and Atmospheric Administration. (2009). What is Climate science literacy. Retrieved September 21, 2017, from https://www.climate.gov/teaching/essentialprinciples-climate-literacy/what-climate-science-literacy

Next Generation Science Standards. 2016. HS. Weather and Climate. Retrieved December 07, 2016, from http://www.nextgenscience.org/topic-arrangement/hsweather-and-climate

Next Generation Science Standards. 2016. MS. Weather and Climate. Retrieved December 07, 2016, from http://www.nextgenscience.org/topic-arrangement/msweather-and-climate

Overpeck, J. T., Meehl, G. A., Bony, S., \& Easterling, D. R. (2011). Climate Data Challenges in the 21st Century. Science, 331(6018), 700-702.

Plutzer, E., Mccaffrey, M., Hannah, A. L., Rosenau, J., Berbeco, M., \& Reid, A. H. (2016). Climate confusion among U.S. teachers. Science, 351(6274), 664-665.

Saldaña, J. (2009). The coding manual for qualitative researchers. Los Angeles: Sage.

Shealy, T., Godwin, A., \& Gardner, H. (2017). Survey Development to Measure the Gap Between Student Awareness, Literacy, and Action to Address Human-caused Climate Change. 2017 ASEE Annual Conference \& Exposition Proceedings.

Shepardson, D. P., Niyogi, D., Roychoudhury, A., \& Hirsch, A. (2012). Conceptualizing climate change in the context of a climate system: Implications for climate and environmental education. Environmental Education Research,18(3), 323-352.

Snider, Jocelyn (2010). Journalism course at Preston High School. Kingwood, WV.

Solomon, P., Barnard, Y., \& Sandberg, J. (1994). The think aloud method: A practical guide to modelling cognitive processes. Academic Press London.

Statistics Canada. (2003). Survey methods and practices. Ottawa: Statistics Canada.

Teddlie, C., \& Yu, F. (2007). Mixed Methods Sampling: A Typology with Examples. Journal of Mixed Methods Research, 1(1), 77-100.

Vaughan, B. L. (1982). Body Talk Understanding the Secret Language of the Body (1st ed.). Allen, TX: Argus Communications.. 
Appendix A- Focus Group Survey

Demographics Questions:

1. Where are you from (State/Province, Country)?

2. What is your major(s)?

3. What is your class level (ex: senior, junior ...)?

4. Have you ever taken a Physical Geography or Climate based course before? If so please list the name of the course.

5. Did you study climate science in high school?

** Save all maps as a JPEG or Print them as a PDF and email them to a.rochellewilliams@gmail.com .

NARR Online Tool

1. Please follow the link https://www.esrl.noaa.gov/psd/data/gridded/data.narr.html

2. Scroll down to Also Available Plotting Pages

3. Click on the blue link for Monthly/Seasonal Composites

4. Under variable you will need to select $2 \mathrm{~m}$ Air Temperature

5. Leave level at $1000 \mathrm{mb}$

6. Both Beginning month and end month need to be set to Jan

7. Under enter years for composites:

a. In the first row of boxes type 2018

b. In the second box type -1979

8. Set the contour interval to 2

9. Set the temperature range from -10 to 10

10. Change Interpolation to $0.3 \times 0.3$ degrees

11. Change Map Region to USA 
12. Leave all other default settings alone.

13. Click Create Plot

14. Save the image that is produced. This can be done by using the snipping tool. Questions

1. On a scale of 1 to 10 how challenging or easy was it to import the dataset? Challenging Neutral

Easy

$\begin{array}{llllllllll}1 & 2 & 3 & 4 & 5 & 6 & 7 & 8 & 9 & 10\end{array}$

2. On a scale of 1 to 10 how challenging or easy was it to subtract 1979 from 2018 ? Challenging Neutral

Easy

$\begin{array}{llllllllll}1 & 2 & 3 & 4 & 5 & 6 & 7 & 8 & 9 & 10\end{array}$

3. On a scale of 1 to 10 how challenging or easy was it to adjust the temperature range?

Challenging

Neutral

Easy

$\begin{array}{llllllllll}1 & 2 & 3 & 4 & 5 & 6 & 7 & 8 & 9 & 10\end{array}$

4. On a scale of 1 to 10 how challenging or easy was it to set the longitude and latitude?

Challenging

Neutral

Easy

$\begin{array}{llllllllll}1 & 2 & 3 & 4 & 5 & 6 & 7 & 8 & 9 & 10\end{array}$

5. On a scale of 1 to 10 how would you rate the interface of this program? Challenging Neutral

Easy

$\begin{array}{llllllllll}1 & 2 & 3 & 4 & 5 & 6 & 7 & 8 & 9 & 10\end{array}$

6. On a scale of 1 to 10 how challenging or easy was it to export the map once created?
Challenging
Neutral
Easy 
$\begin{array}{llllllllll}1 & 2 & 3 & 4 & 5 & 6 & 7 & 8 & 9 & 10\end{array}$

7. On a scale of 1 to 10 how would you rate the usability of the NARR online tool? $\begin{array}{lll}\text { Challenging } & \text { Neutral } & \text { Easy }\end{array}$

$\begin{array}{llllllllll}1 & 2 & 3 & 4 & 5 & 6 & 7 & 8 & 9 & 10\end{array}$

8. On a scale of 1 to 10 is this map easy or challenging to interpret? $\begin{array}{lll}\text { Challenging } & \text { Neutral } & \text { Easy }\end{array}$

$\begin{array}{llllllllll}1 & 2 & 3 & 4 & 5 & 6 & 7 & 8 & 9 & 10\end{array}$

9. On a scale of 1 to 10 is the scale bar easy or challenging to interpret? Challenging Neutral Easy

$\begin{array}{llllllllll}1 & 2 & 3 & 4 & 5 & 6 & 7 & 8 & 9 & 10\end{array}$

10. According to the map which part of the United States has the largest temperature increase compared to 1979 ?

11. What do you like best about this map? What do you dislike about this map?

12. Is there anything else you wish to comment about this map?

13. Is there anything else you wish to comment about this program?

\section{Panoply}

1. Open the Panoply tool on the computer:

a. Click the folder icon on the task bar

b. Click This PC in the side panel of the window

c. Double click the folder PanoplyWin

d. Then double click Panoply (it has a globe icon next to it).

2. Go to the start menu on the desktop, find FileZilla and open it 
3. New Site:

a. Host: climate.geo.wvu.edu

b. User: geofg\#

c. Password: geofg

d. Port: 22

4. Click Quickconnect

5. Under the window Remote Site double click geofg\# folder

6. Now copy the following files from the server to the computer desktop

a. 1979_Jan_Temp.nc

b. 2018_Jan_Temp.nc

*Hint you can do this by simply clicking and holding the file then dragging it from the right lower window to the left lower window.

7. Minimize File Zilla

8. When the Panoply: Sources window opens go to

a. file- open, select desktop

b. $\quad$ select file 1979_Jan_Temp.nc

c. click open

9. Repeat the above steps for file named 2018_Jan_Temp.nc

10. Click the variable air

11. Click create plot

12. Click create

13. Repeat these steps for the 2018 temperature file

*Note you will need to create a plot for 1979 before 2018

14. Once both plots have been created go back to the Panoply source window 
15. Click combine plot

16. Under the drop down make sure 1979 is selected

17. Click combine

18. In the 1979_Jan_Temp plot window you should now see 2 Arrays under the array tab.

19. Set the time step for both arrays to January of the correct year. Example: 4=April 1979. The number represents the month of all the years combined.

20. Still under the array tab change plot of to Array 2-Array 1 (2018-1979)

21. Under the scale tab

a. Scale range: click the fit to data button

b. Make the min and max temperature range from -10 to 10

c. Change the units to Kelvin

22. Under the map tab

a. Projection: change to Equirectangular (Regional)

b. Center on: Lon, Lat select the best Longitude and Latitude that

i. $\quad$ center over the United States. Example Lon: -120 Lat: 20.

c. Click Fix Proportions

23. Under the Overlays tab

a. Overlay 1: change to MWDB_Coasts_USA_1.cnob

24. Save the image you have just created as a JPEG.

Questions:

1. On a scale of 1 to 10 how challenging or easy was it to import the dataset? Challenging Neutral

Easy

$\begin{array}{llllllllll}1 & 2 & 3 & 4 & 5 & 6 & 7 & 8 & 9 & 10\end{array}$


2. On a scale of 1 to 10 how challenging or easy was it to subtract 1979 from 2018 ? Challenging Neutral

Easy

$\begin{array}{llllllllll}1 & 2 & 3 & 4 & 5 & 6 & 7 & 8 & 9 & 10\end{array}$

3. On a scale of 1 to 10 how challenging or easy was it to adjust the temperature range?

Challenging

Neutral

Easy

$\begin{array}{llllllllll}1 & 2 & 3 & 4 & 5 & 6 & 7 & 8 & 9 & 10\end{array}$

4. On a scale of 1 to 10 how challenging or easy was it to set the longitude and latitude?

Challenging

Neutral

Easy

$\begin{array}{llllllllll}1 & 2 & 3 & 4 & 5 & 6 & 7 & 8 & 9 & 10\end{array}$

5. On a scale of 1 to 10 how would you rate the interface of this program?

Challenging

Neutral

Easy

$\begin{array}{llllllllll}1 & 2 & 3 & 4 & 5 & 6 & 7 & 8 & 9 & 10\end{array}$

6. On a scale of 1 to 10 how challenging or easy was it to export the map once created?

Challenging

Neutral

Easy

$\begin{array}{llllllllll}1 & 2 & 3 & 4 & 5 & 6 & 7 & 8 & 9 & 10\end{array}$

7. On a scale of 1 to 10 how would you rate the usability of Panoply?

Challenging

Neutral

Easy

$\begin{array}{llllllllll}1 & 2 & 3 & 4 & 5 & 6 & 7 & 8 & 9 & 10\end{array}$

8. On a scale of 1 to 10 is this map easy or challenging to interpret?

Challenging

Neutral

Easy

$\begin{array}{llllllllll}1 & 2 & 3 & 4 & 5 & 6 & 7 & 8 & 9 & 10\end{array}$

9. On a scale of 1 to 10 is the scale bar easy or challenging to interpret? 
Challenging

Neutral

Easy

$\begin{array}{llllllllll}1 & 2 & 3 & 4 & 5 & 6 & 7 & 8 & 9 & 10\end{array}$

10. According to the map which part of the United States has the largest temperature increase compared to 1979 ?

11. What do you like best about this map? What do you dislike about this map?

12. Is there anything else you wish to comment about this map?

13. Is there anything else you wish to comment about this program?

Grid Analysis and Display System (GrADS)

1. Open MobaXterm

2. Click sessions

3. Click New Session

4. Click SSH

a. Host: climate.geo.wvu.edu

b. Port: 22

5. Click connect

6. Type the following with your assigned number

a. geofg\#

b. password: geofg

7. Minimize the window

8. Go to the start menu on the desktop, find FileZilla and open it

9. New Site:

a. Host: climate.geo.wvu.edu

b. User: geofg\# 
c. Password: geofg

d. Port: 22

10. Click Quickconnect

11. Under the window Remote Site double click geofg\# folder

12. Now copy the following files from the server to the computer desktop

a. 2018_1979_comp.gs

b. GrADS_Jan_temp.ddf

c. 1979_Jan_Temp.nc

*Hint you can do this by simply clicking and holding the file then dragging it from the right lower window to the left lower window.

13. Minimize File Zilla

14. In MobaXterm go to the tools tab $\square$ select text editor

15. Choose the file GrADS_Jan_temp.ddf. (ddf means data descriptor file)

*You will notice there are mistakes in the code. These are the areas you will need to fill out to produce a graphic.

16. On line 1 type the data's file name to display January 1979. Example:

2012_Precip.nc

17. On line 10 make sure the line is set to January of the correct year.

a. Example: tdef 469 linear 00z03mar2012 1mo

18. Once these steps are complete save the edited file. Leave this file open.

19. In a new text editor window open the file 2018-1979_comp.gs

*You will notice there are blanks and mistakes in the code. These are the areas you will need to fill out to produce a graphic.

20. On line 8 type the file name of the source file you wish to display. (Hint: the data descriptor file) 
a. Example: 'open GrADS_Mar_Precip.ddf '.

21. Once the time step is adjusted move onto 'set lon \# \#' and 'set lat \# \#' . Hint:

NARR data Longitude is 0-360 degrees, and Latitude is 0-90.

a. $\quad$ Example: 'set lat 2838 '

'set lon 265275 '

22. Now you need to adjust the time step for January $(\mathrm{t}=\#)$. Example March 1979 is $\mathrm{t}=3$ and June $2010 \mathrm{t}=378$

23. On line 73 set the temperature difference range from -10 to 10. (Hint: go by 2's, 0 is not needed)

24. On line 121 give the map a proper title with Kelvin as your units.

25. On line122 type the years in order of subtraction.

26. Once these steps are complete save the edited file. Leave this file open.

27. Reopen File Zilla

28. Click the refresh button (hint it looks like this )

29. Now copy the two files you have just edited to the server.

30. Once complete minimize FileZilla

31. Open the command window in MobaXterm.

32. In the command window type "source .bashrc"

33. Then in the command window type "grads"

34. Hit the enter key twice

35. A blank black window should pop-up on the desktop. Do not close this window.

36. Click into the command window again

37. Type the command "run 2018-1979_comp.gs".

38. In the blank black window you should now see the image of the data.

39. This image will be exported as "grads.eps". 
Questions:

1. On a scale of 1 to 10 how challenging or easy was it to import the dataset? Challenging Neutral

Easy

$\begin{array}{llllllllll}1 & 2 & 3 & 4 & 5 & 6 & 7 & 8 & 9 & 10\end{array}$

2. On a scale of 1 to 10 how challenging or easy was it to subtract 1979 from 2018 ? Challenging Neutral Easy

$\begin{array}{llllllllll}1 & 2 & 3 & 4 & 5 & 6 & 7 & 8 & 9 & 10\end{array}$

3. On a scale of 1 to 10 how challenging or easy was it to adjust the temperature range?

Challenging

Neutral

Easy

$\begin{array}{llllllllll}1 & 2 & 3 & 4 & 5 & 6 & 7 & 8 & 9 & 10\end{array}$

4. On a scale of 1 to 10 how challenging or easy was it to set the longitude and latitude?

Challenging

Neutral

Easy

$\begin{array}{llllllllll}1 & 2 & 3 & 4 & 5 & 6 & 7 & 8 & 9 & 10\end{array}$

5. On a scale of 1 to 10 how would you rate the interface of this program?

Challenging

Neutral

Easy

$\begin{array}{llllllllll}1 & 2 & 3 & 4 & 5 & 6 & 7 & 8 & 9 & 10\end{array}$

6. On a scale of 1 to 10 how challenging or easy was it to export the map once created?

Challenging

Neutral

Easy 
$\begin{array}{llllllllll}1 & 2 & 3 & 4 & 5 & 6 & 7 & 8 & 9 & 10\end{array}$

7. On a scale of 1 to 10 how would you rate the usability of GrADS? Challenging Neutral Easy

$\begin{array}{llllllllll}1 & 2 & 3 & 4 & 5 & 6 & 7 & 8 & 9 & 10\end{array}$

8. On a scale of 1 to 10 is this map easy or challenging to interpret? Challenging Neutral Easy

$\begin{array}{llllllllll}1 & 2 & 3 & 4 & 5 & 6 & 7 & 8 & 9 & 10\end{array}$

9. On a scale of 1 to 10 is the scale bar easy or challenging to interpret?

\begin{tabular}{ccccccccccc}
\multicolumn{3}{c}{ Challenging } & \multicolumn{3}{c}{ Neutral } & & & & \\
& 1 & 2 & 3 & 4 & 5 & 6 & 7 & 8 & 9 & 10
\end{tabular}

10. According to the map which part of the United States has the largest temperature increase compared to 1979 ?

11. What do you like best about this map? What do you dislike about this map?

12. Is there anything else you wish to comment about this map?

13. Is there anything else you wish to comment about this program? 


\section{Appendix B-Grid Analysis and Display System Code}

$* * * *$ By Dr. Eungul Lee

**** Modified by A. R. Williams for Focus Group Survey

$* * * *$ Modified Spring 2018

$* *$ Composite (difference)

* Return to initial state: It closes all open files, releases all defined variables, and resets all graphics settings to their defaults.

'reinit'

** Open data: Open a NetCDF format file from the directory where it is.

* Temperature: variable name 'air' in units of 'Kelvin'

'open GrADS_Jan_temp.ddf'

'clear'

'set grads off'

* Set longitude coordinates for the map: default from lon $0 \mathrm{deg}$ to $0 \mathrm{deg}$

* Set center of the map to UK (longitude $0 \mathrm{deg}$ )

'set lon -180180 '

* Set map resolution

* 'lowres': default, 'mres' and 'hires': state and country outlines, 'nmap' only for North America

'set mpdset hires'

* Set color,thickness, size of lat and lon numbers

'set xlopts 1. 6. 0.2'

'set ylopts 1. 6. 0.2'

* Set line color,style,thickness of map

'set map 1. 1. 6.'

* Set lon and lat regions you're interested in.

* U.S.

'set lat 2050 '

'set lon 230295 '

* Set lat(ylint) and lon(xlint) interval

* U.S.

'set ylint 5.'

'set xlint 10.'

*******************************

** Step 1. Define variable

* Monthly

* Jan

* 'define $\mathrm{x} 61=\mathrm{air}(\mathrm{t}=721)^{\prime}$

* 'define x62=air $(\mathrm{t}=733)$ '

* 'define $\mathrm{x} 63=\operatorname{air}(\mathrm{t}=745)$ '

* 'define x64=air $(\mathrm{t}=757)$ '

* 'define x65=air $(\mathrm{t}=769)$ '

* 'define x66=air $(\mathrm{t}=781)$ '

* 'define x67=air(t=793)' 
* 'define $x 68=\operatorname{air}(\mathrm{t}=805)$ '

* 'define x69=air $(\mathrm{t}=817)$ '

* 'define x70=air $(\mathrm{t}=829)$ '

* 'define x71=air $(\mathrm{t}=841)$ '

* 'define x72=air $(\mathrm{t}=853)$ '

* 'define x73=air $(\mathrm{t}=865)$ '

* 'define x74=air $(\mathrm{t}=877)$ '

* 'define x75=air $(\mathrm{t}=889)$ '

* 'define x76=air $(\mathrm{t}=901)$ '

* 'define $\mathrm{x} 77=\operatorname{air}(\mathrm{t}=913)$ '

* 'define x78=air $(\mathrm{t}=925)$ '

* 'define x79=air $(\mathrm{t}=937)$ '

* 'define $\mathrm{x} 80=\mathrm{air}(\mathrm{t}=949)$ '

* 'define x81=air $(\mathrm{t}=961)$ '

* 'define x82=air $(\mathrm{t}=973)$ '

* 'define x83=air $(\mathrm{t}=985)$ '

* 'define x84=air $(\mathrm{t}=997)$ '

* 'define $\mathrm{x} 85=\mathrm{air}(\mathrm{t}=1009)$ '

* 'define x86=air $(\mathrm{t}=1021)$ '

* 'define x87=air $(\mathrm{t}=1033)$ '

* 'define $\mathrm{x} 88=\operatorname{air}(\mathrm{t}=1045)$ '

* 'define $\mathrm{x} 89=\mathrm{air}(\mathrm{t}=1057)$ '

* 'define x90=air $(\mathrm{t}=1069)$ '

*Month

'define $\mathrm{x} 1=\mathrm{air}(\mathrm{t}=469)$ '

'define $\mathrm{x} 2=\operatorname{air}(\mathrm{t}=1)$ '

say 'Step 1: X variable defined'

$* * * * * * * *$

** Step 2. Calculate mean difference $\mathrm{b} / \mathrm{w}$ five strong and five weak years

* Calculate the difference of Jan 1979 ('mxa') and Jan 2018 ('mxb') years

* Temperature for January 1979 and January 2018

'define $m x a=(x 1) / 1$.'

'define $m x b=(x 2) / 1$.'

* Calculate difference b/w January 1979 and January 2018

'define diff=mxa-mxb'

say 'Step 2: calculate composite difference'

**********************************

** Setting and Display the variable

* Set shaded contour plot

'set gxout shade1'

* Sets specific contour levels

* Precip 
* 'set clevs -20. -15. -10. -5. -1. 1. 5. 10. 15. 20.'

'set clevs -10. -8. -6. -4. -2. 2. 4. 6. 8. 10.'

$*$

* Defining new color RGB scheme

* BLUE shades (for negative cor)

'set rgb $16 \quad 0 \quad 0$ 255'

'set rgb 17115115255 '

'set rgb $18160160255^{\prime}$

'set rgb $19200200255^{\prime}$

'set rgb $20230230255^{\prime}$

* RED shades (for positive cor)

'set rgb 21255230230 '

'set rgb 22255200200 '

'set rgb 23255160160 '

'set rgb 24255115115 '

'set rgb $25255 \quad 0 \quad 0$ '

* Set colors for the contour using the defined scheme

* Precip: Red to Blue

*'set ccols 2524232221020191817 16'

* Temp: Blue to Red

'set ccols $161718192002122232425^{\prime}$

* Display

'd diff'

* Display scale bar

'run /Users/geog517/cbarn.gs'

** Contour significant region (t statistics)

'set gxout contour'

* Delete label of contour

'set clopts 100 '

* Set Thickness of contour 'set cthick 10'

* Set 'Critical Values of t statistics' using the table from http://www.jeremymiles.co.uk/misc/tables/t-test.html

$* \mathrm{df}=\min (\mathrm{n} 1-1, \mathrm{n} 2-1)=4$ for two tailed: $90 \%(\mathrm{p}=0.1)=2.13,95 \%(\mathrm{p}=0.05)=2.78,99 \%(\mathrm{p}=0.01)=4.6$

* http://ccr.aos.wisc.edu/climate_modeling/modeling/data_processing/grads/grads_statsig.php

* Contour the line of $\mathrm{t}=2.13$ ( $\mathrm{sig}$ at $90 \%$ )

'set clevs 2.13'

'd t'

say 'Significant regions contoured'

* Write title and subtitle:! Display on the screen but not in the output file t1='Temperature Difference 2018-1979(K)'

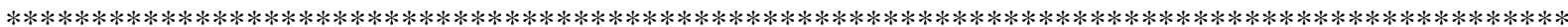

$*$ Lines below for title (t1) and subtitle (t2) 


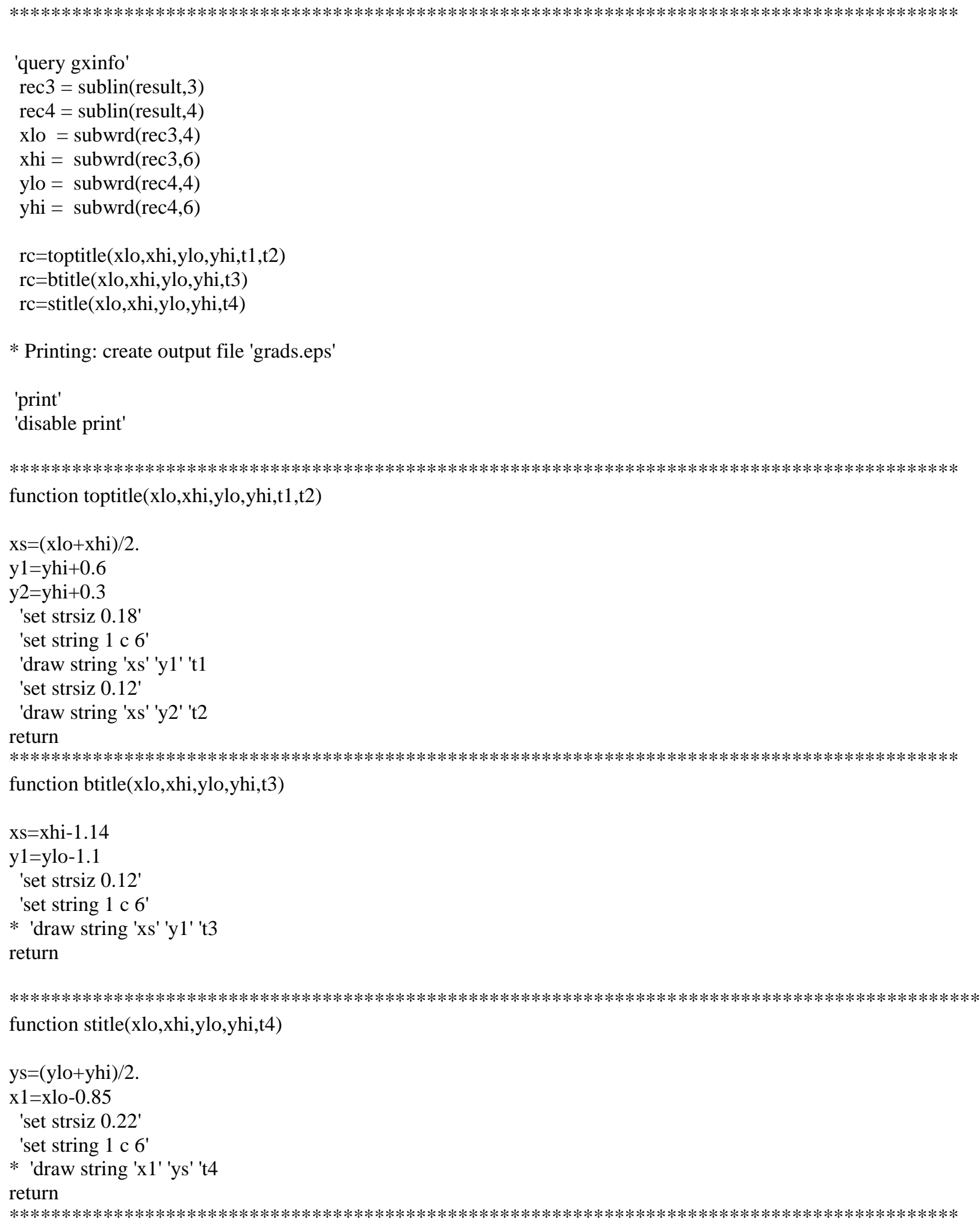


Appendix C-Map outputs

NOAA online tool

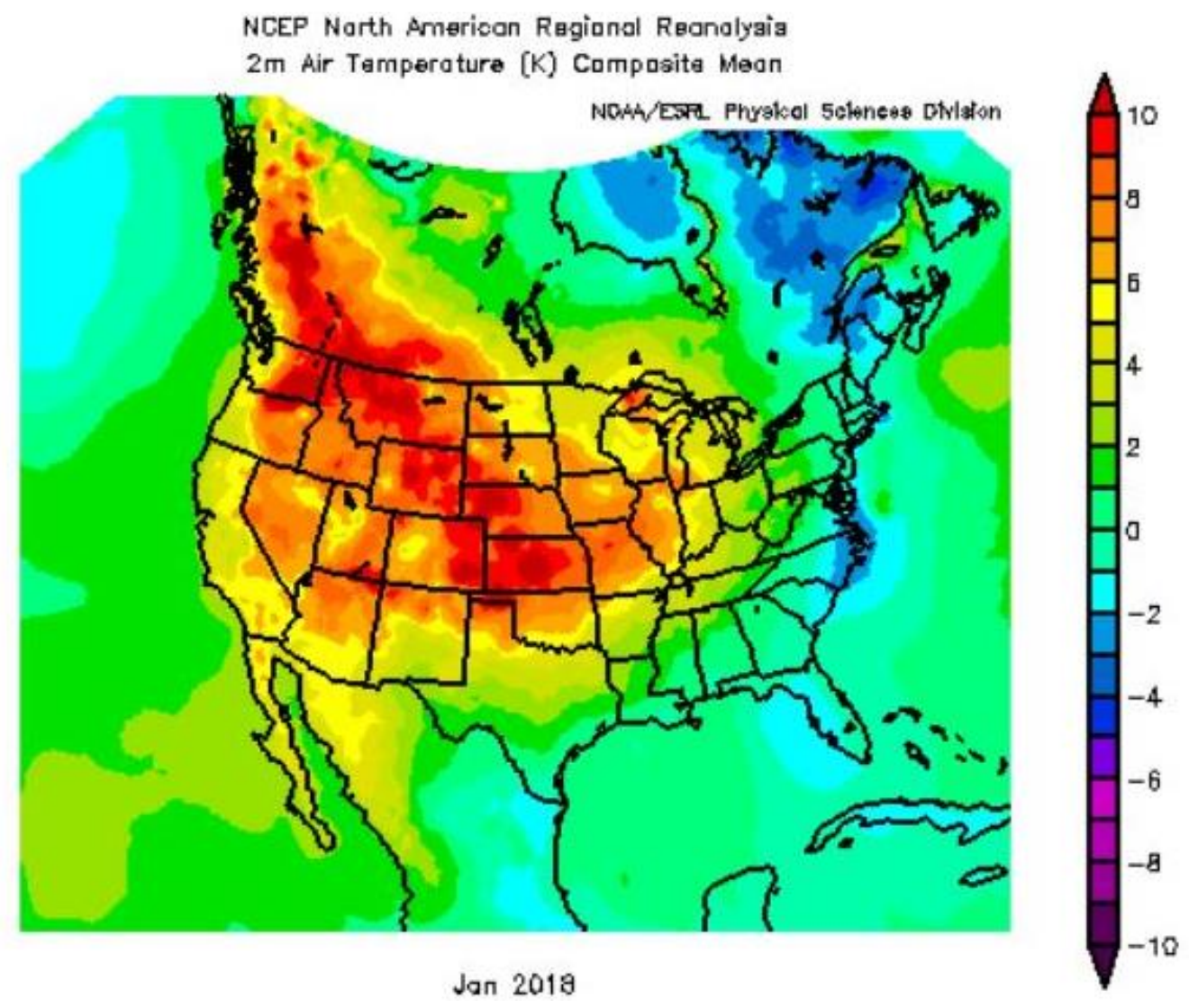


Panoply data viewer

Monthly Air Temperature at $2 \mathrm{~m}$

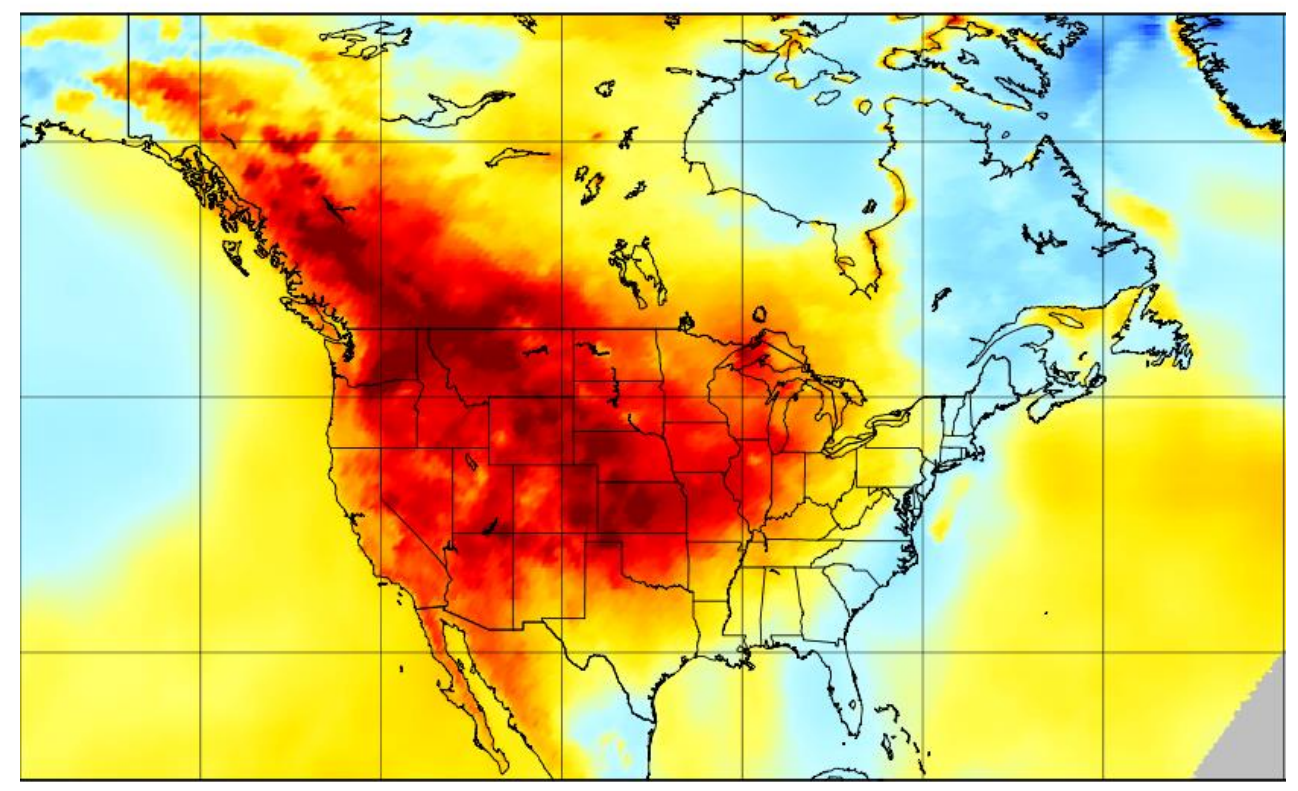

Monthly Air Temperature at $2 \mathrm{~m}$ - Monthly Air Temperature at $2 \mathrm{~m}(\mathrm{~K})$
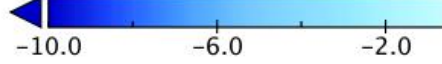

Data $\operatorname{Min}=-9.7, \operatorname{Max}=13.6$

6.0

10.0 


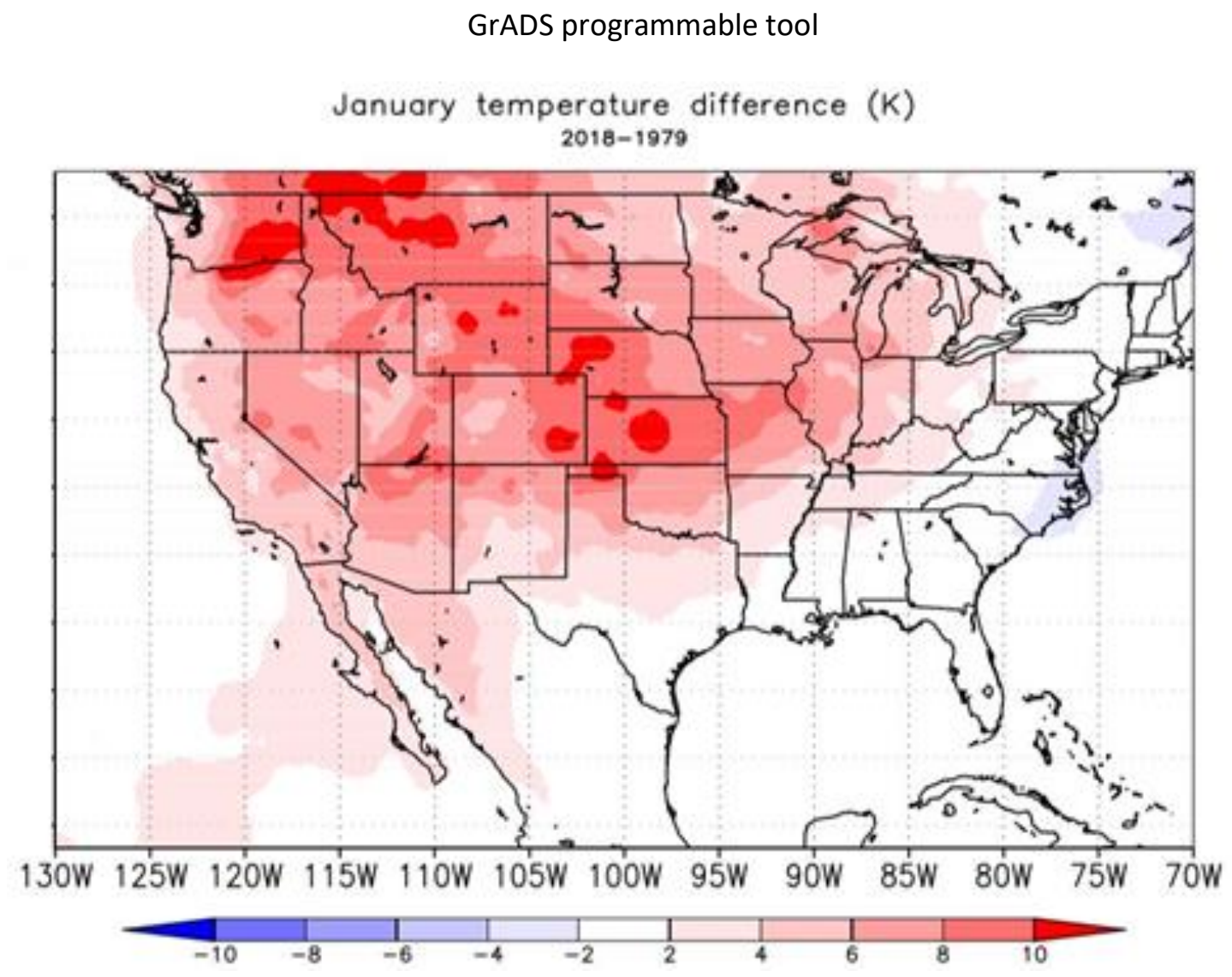

